Review

\title{
Multifunctional Nature of the Arenavirus RING Finger Protein Z
}

\section{Sarah Katharina Fehling ${ }^{\dagger}$, Frank Lennartz ${ }^{\dagger}$ and Thomas Strecker *}

Institut für Virologie der Philipps-Universität Marburg, Hans-Meerwein-Str. 2, 35043 Marburg, Germany; E-Mails: fehling@staff.uni-marburg.de (S.K.F.), lennartz@students.uni-marburg.de (F.L.), strecker@staff.uni-marburg.de (T.S.)

$\dagger$ These authors contributed equally to this work.

* Author to whom correspondence should be addressed; E-Mail: strecker@staff.uni-marburg.de; Tel.: +49-6421-28 66254, Fax: +49-6421-28 65182.

Received: 4 October 2012; in revised form: 4 November 2012 / Accepted: 5 November 2012 / Published: 9 November 2012

\begin{abstract}
Arenaviruses are a family of enveloped negative-stranded RNA viruses that can cause severe human disease ranging from encephalitis symptoms to fulminant hemorrhagic fever. The bi-segmented RNA genome encodes four polypeptides: the nucleoprotein NP, the surface glycoprotein GP, the polymerase L, and the RING finger protein Z. Although it is the smallest arenavirus protein with a length of 90 to 99 amino acids and a molecular weight of approx. $11 \mathrm{kDa}$, the $\mathrm{Z}$ protein has multiple functions in the viral life cycle including (i) regulation of viral RNA synthesis, (ii) orchestration of viral assembly and budding, (iii) interaction with host cell proteins, and (iv) interferon antagonism. In this review, we summarize our current understanding of the structural and functional role of the $\mathrm{Z}$ protein in the arenavirus replication cycle.
\end{abstract}

Keywords: Arenavirus; ESCRT; Lassa virus; Lymphocytic choriomeningitis virus; Junin virus; matrix protein; RING finger protein; virus assembly and budding; virus-host cell interaction; $\mathrm{Z}$ protein 


\section{Introduction}

The Arenaviridae family consists of one unique genus (Arenavirus) that currently comprises 24 recognized virus species as defined by the International Committee on Taxonomy of Viruses. According to their antigenic properties, their serological relationships and their geographical distribution, arenaviruses have been classified into two groups: the New World (NW) and the Old World (OW) group (Fig. 1). NW arenaviruses can be further divided into three clades (A, B, and C), based on the sequence of their nucleocapsid genes. The OW group includes the globally distributed prototypic arenavirus, lymphocytic choriomeningitis virus (LCMV), as well as the highly human pathogenic Lassa virus (LASV), which is the causative agent of the acute viral hemorrhagic Lassa fever found in West Africa; and Lujo virus (LUJV) that has been associated with severe hemorrhagic fever disease in five patients in southern Africa [1-3]. OW arenaviruses found throughout the African continent but not known to be pathogenic for humans are Ippy (IPPV), Mobala (MOBV), Mopeia (MOPV), Morogoro, and Kodoko viruses [4-6]. Among others, the NW complex comprises Junin virus (JUNV) in Argentina, Chapare (CHPV) and Machupo viruses (MACV) in Bolivia, Sabia virus (SABV) in Brazil, Tacaribe virus (TCRV) in Trinidad, Whitewater Arroyo virus (WWAV) in the United States, and Guanarito virus (GTOV) in Venezuela [7-9]. Five of the South American arenaviruses (CHPV, GTOV, JUNV, MACV, and SABV) are associated with hemorrhagic fever (HF) in humans and, together with LASV and LUJV, they make arenaviruses to the largest currently known family of HF-causing viruses.

Figure 1. Geographic distribution of human pathogenic arenaviruses. This map summarizes the distribution of human pathogenic New and Old World arenavirus species. The year of the first description is indicated in brackets.

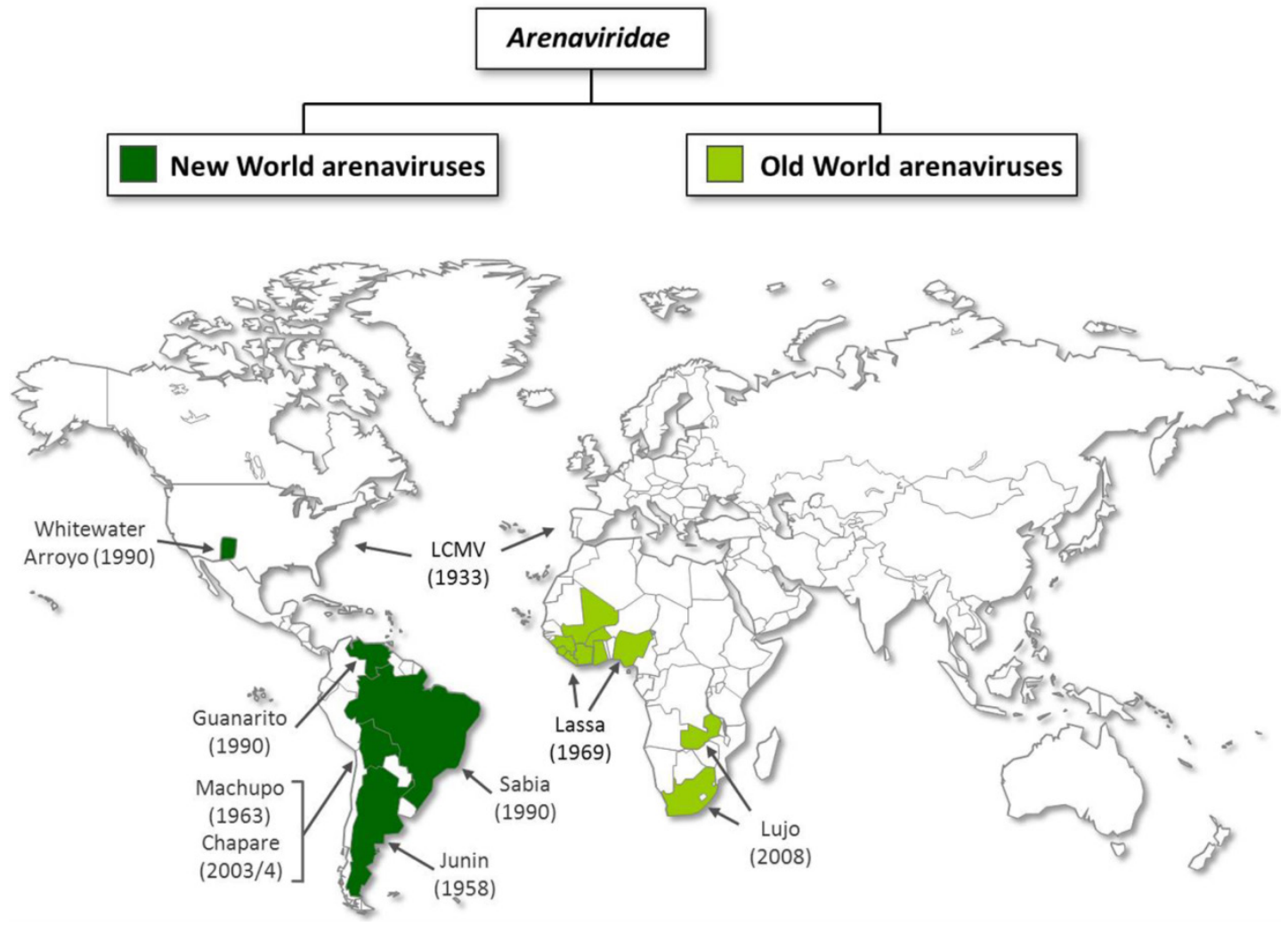


The principal hosts of NW and OW arenaviruses are rodents, and the only exception to date is TCRV which was isolated from fruit-eating bats [10]. However, recent studies showed that TCRV causes fatal infection in Jamaican fruit bats (Artibeus jamaicensis), indicating that these may not be the natural reservoir host for TCRV [11]. The geographic distribution of each arenavirus is determined by the range of habitats of its reservoir species. LCMV is the only arenavirus known to be distributed worldwide due to its association with its wide-spread host Mus musculus. Transmission of arenaviruses from their respective hosts to humans is assumed to occur mainly through inhalation of particulates contaminated with infectious rodent excretions. In addition, hunting of peridomestic rodents and consumption of their meat as a protein source are recognized as potential risk factors for rodent-tohuman transmission of LASV in certain regions of Guinea [12]. Direct contact with blood and body fluids or contaminated materials from highly viraemic patients significantly increases the risk of human-to-human transmission of HF arenaviruses during nosocomial outbreaks [13,14].

Among HF-causing arenaviruses, the known distribution of LASV covers the greatest geographical range, being endemic in several West African countries, with outbreaks most frequently observed in Guinea, Liberia, Nigeria, and Sierra Leone [15-21]. Virus isolation or serological evidence of human LASV infection has also been documented in the Central African Republic, Ivory Coast, Mali, and Senegal [22-26]. Therefore, LASV constitutes a significant public health burden, with more than 220 million people living at potential risk in these countries. Additionally, due to increased air travel and inter-regional travel, as well as international peacekeeping in areas of conflict in which LASV is endemic, LASV has been transported numerous times to Europe, North America, and Japan, making it responsible for the largest number of reported cases of imported viral hemorrhagic fevers (VHF) in industrial countries [27,37].

In spite of the threat that HF arenaviruses pose, the live attenuated JUNV vaccine known as Candid \#1 is currently the only vaccine that has been found to be safe and highly efficacious against JUNV infection when tested in endemic areas [38], although progress in the development of effective vaccines for other arenaviruses has been reported [39,40]. The only existing drug used to treat Lassa fever and certain South American VHFs is the broad-spectrum antiviral agent Ribavirin, a ribonucleoside analog, that has been shown to be partially effective if administered in the early course of illness [41]. Due to the severe and often fatal outcome of infection, non-availability of vaccine prophylaxis, and inadequate therapeutic treatment options, HF arenaviruses are defined as Category A Priority Pathogens by the National Institute of Allergy and Infectious Diseases (NIAID), and are listed as Biosafety Level 4 (BSL-4) agents.

\section{Virion architecture, gene organization and virus replication}

Arenaviruses are lipid-enveloped viruses containing a bi-segmented negative-strand RNA genome. Each genomic RNA segment encodes two non-overlapping open reading frames in an ambisense orientation, separated by a non-coding intergenic region. The small (S) RNA encodes the nucleoprotein NP and the glycoprotein precursor preGP-C, which undergoes co- and post-translational cleavage events in order to achieve its mature form [42-45]. The large (L) RNA segment encodes the RNA-dependent RNA polymerase L and the small RING finger protein Z [46-49]. Arenavirus virions are spherical or pleomorphic and vary in diameter from 60 to 300 nanometers (Fig. 2A). It is assumed 
that the lipid bilayer of the viral envelope derives from the host cell membrane where arenavirus budding occurs. The virion surface is covered with trimeric glycoprotein spike complexes [50,51]. Within the virion, a matrix layer composed of $Z$ protein lines the inner leaflet of the membrane [5153]. Solitary expression of $Z$ protein is sufficient for the production of lipid-enveloped virus-like particles (VLPs) that are morphologically similar to virus particles released from infected cells [54]. The genomic RNAs are thought to assemble with L and NP proteins into ribonucleoprotein complexes (RNPs). A schematic representation of the virion architecture and gene organization of arenaviruses is shown in Fig. 2 (B and C).

Figure 2. Arenavirus virion structure and genome organization. (A) Electron microscopic image of Lassa virus (LASV) illustrates the common virion architecture of arenaviruses. Bar, 100nm. (B) Schematic representation of arenavirus virions. The viral envelope, a lipid bilayer derived from the host cell plasma membrane, contains multiple copies of glycoprotein spikes on the surface that are required for receptor binding and virus entry. The $\mathrm{Z}$ protein forms a matrix layer underneath the viral membrane. The nucleoprotein NP associates with the polymerase $\mathrm{L}$ to form together with the genomic RNA the ribonucleoprotein (RNP) complex. (C) Genome organization of arenaviruses. Arenaviruses contain a bi-segmented negative-strand RNA genome, composed of the small (S) RNA segment and the large (L) RNA segment. Each RNA segment encodes two viral proteins in an ambisense orientation. The open reading frames are separated by intergenic regions.

A

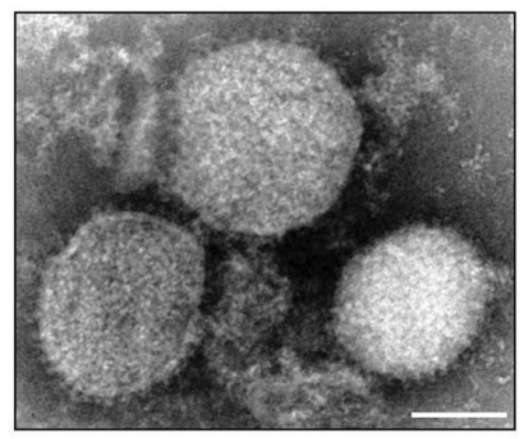

B

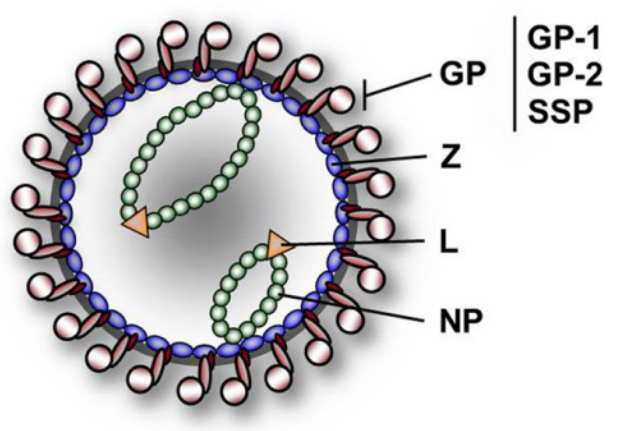

C

\section{S-RNA (3.4 kb)}

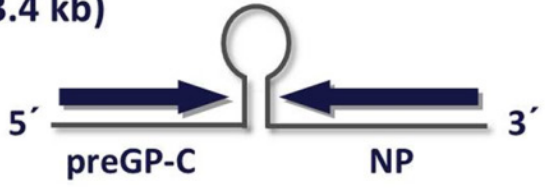

L-RNA (7.2 kb)

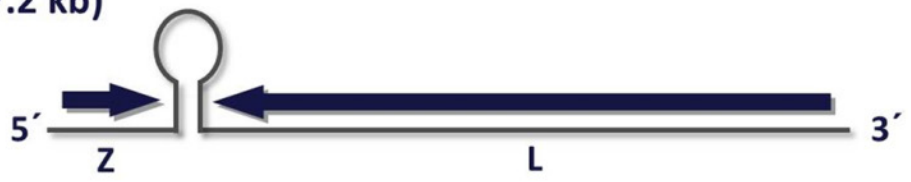


For virus entry into host cells, OW arenaviruses and Clade C NW arenaviruses use $\alpha$-dystroglycan as a cellular receptor [55,56], which normally functions as a transmembrane linkage between the actin-based cytoskeleton and the extracellular matrix. Although $\alpha$-dystroglycan is presumably the main receptor for LASV and LCMV, recent findings suggested the existence of four alternative receptor molecules: DC-SIGN and LSECtin from the C-type lectin family, and the receptor tyrosine kinases Tyro3 and Axl [57,58]. However, the role these molecules play in cell-specific targeting and tissue tropism of LASV and other arenaviruses in vivo remains unclear. Clade B NW arenaviruses employ the transferrin receptor 1 (TfR1) as an entry receptor for the infection of target cells [59], while the cellular receptor for Clade A NW arenaviruses has not yet been identified. Upon receptor binding, NW arenaviruses enter the host cells through clathrin-mediated endocytosis [60], while the internalization route of OW arenaviruses is clathrin-independent [61-63]. Recent studies demonstrated that LASV and LCMV cell entry occurs through late endosomes/multivesicular bodies (MVBs). This novel arenavirus entry pathway is thought to be linked to the cellular trafficking and degradation route of $\alpha$ dystroglycan [64]. The low pH environment of late endosomes is necessary for the virus-endosome membrane fusion triggered by the glycoprotein GP [65]. Following the release of the RNPs into the host cell cytoplasm, viral replication and transcription are initiated.

During genome replication, a full-length, anti-genomic copy of the genomic S and L RNA is synthesized. The purified genomic and antigenomic RNA species alone are unable to direct the synthesis of viral polypeptides and thus are not infectious. Due to the ambisense coding strategy, both genomic and anti-genomic RNA serve as templates for transcription of viral mRNA. The transcripts contain a 5 cap but are not polyadenylated [66]. The first synthesized viral proteins are NP and L, which represent the minimal viral trans-acting factors required for efficient viral RNA synthesis [67,68]. GP-C and Z are transcribed from the anti-genomic RNA of the $\mathrm{S}$ and L segments. The anti-genomic RNA also serves as a template for the generation of genomic RNA segments, which, together with NP and L, associate to RNPs. Finally, the RNPs are packaged and progeny virions are released from the cell. The membrane derived from the host cell that envelopes the budding virus particles bears the envelope glycoprotein GP.

\section{The multiple roles of $Z$ protein in the arenavirus life cycle}

Due to their small genome size and small number of genes, arenaviruses evolved a powerful strategy for maintaining efficient virus replication by encoding multifunctional viral proteins that mediate several distinct virus-virus and/or virus-host protein-protein interactions. In particular, the smallest arenavirus gene product, the RING finger protein $Z$, has multiple functions and acts at various stages during viral infection. As illustrated in Fig. 3, essential functions of the $\mathrm{Z}$ protein include (i) regulation of viral RNA synthesis, (ii) orchestration of viral assembly and budding, (iii) interaction with host cell proteins, and (iv) antagonizing the host cell interferon (IFN) system. In the following sections we will review the current knowledge on this remarkably multifunctional viral protein and discuss how the $\mathrm{Z}$ protein facilitates its various activities. 
Figure 3. Functional roles of the arenavirus $Z$ protein in the viral life cycle. Regulation of viral RNA synthesis. Transcription and replication of arenaviruses takes place in the host cell cytoplasm. $Z$ protein regulates these processes through interaction with the viral polymerase. Orchestration of viral assembly and budding. $Z$ protein drives particle release at the plasma membrane. Through interaction with GP and viral RNPs, Z mediates their incorporation into nascent virions. Interaction with host cell proteins. $Z$ protein interacts with several host cell factors, such as PML (promyelocytic leukemia protein), eIF4E (eukaryotic translation initiation factor 4E), PRH (proline-rich homeodomain protein), and ribosomal $P$ proteins. The assumed biological effects of these interactions on arenavirus replication are discussed in the text. Interferon antagonism. $Z$ proteins from various NW arenaviruses participate in IFN antagonism. While $Z$ protein inhibits the activation of RIG-I-mediated downstream signalling pathway through direct interaction with RIG-I, NP, which is the main arenavirus interferon antagonist, causes a block in the IRF-3 activation pathway and prevents nuclear translocation of IRF-3.

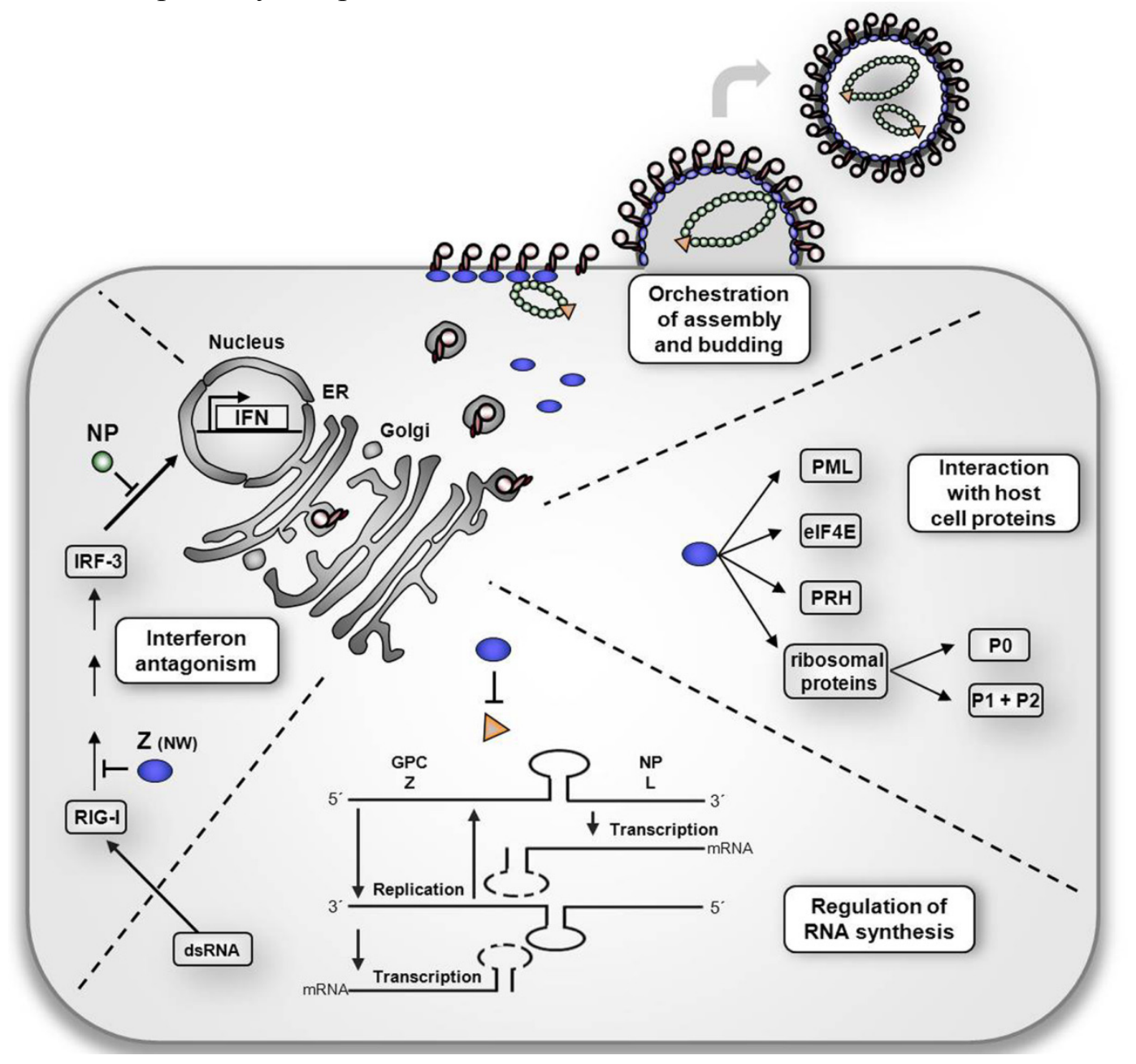


Figure 4. Schematic representation of the linear organization of arenavirus $Z$ protein. (A) Domain structure of the $\mathrm{Z}$ protein. The $\mathrm{Z}$ protein contains an $\mathrm{N}$-terminal myristoylation site for attachment of myristic acid (shown in red), and a conserved, centrally located RING domain, which coordinates the binding of two zinc atoms. Structural characterization of LASV Z protein suggested that the N- (residue 1-29) and the Cterminal (residue 71-99) arms flanking the RING domain are highly flexible, enabling $Z$ protein to exhibit different conformational states. The C-terminal part harbours the late domains. (B) Comparison of $\mathrm{OW}$ and NW arenavirus $\mathrm{Z}$ proteins. The N-terminal myristoylation site and the YxxL-late domain motif are conserved within both OW and NW arenaviruses. C-terminally located late domains differ between $\mathrm{OW}$ and NW virus species both in their number as well as their relative position. Gene bank accession numbers for viral sequences: Lassa virus (LASV, NP_694871.1), Lymphocytic choriomeningitis virus (LCMV, P18541), Lujo virus (LUJV, YP_002929492), Mopeia virus (MOPV, AEO89357), Mobala virus (MOBV, YP_516228), Ippy virus (IPPV, YP 516232), Whitewater Arroyo virus (WWAV, YP_001911119), Pichinde virus (PICV, AAL16100), Pirital virus (PIRV, YP_025092), Junin virus (JUNV, AFA53095), Machupo virus (MACV, AAT45079), Chapare virus (CHAV, YP_001816784), Tacaribe virus (TCRV, NP_694847), Guanarito virus (GTOV, NP_899220), Sabia virus (SABV, YP_089659), Latino virus (LATV, YP_001936025), Oliveros virus (OLVV, YP_001649215).

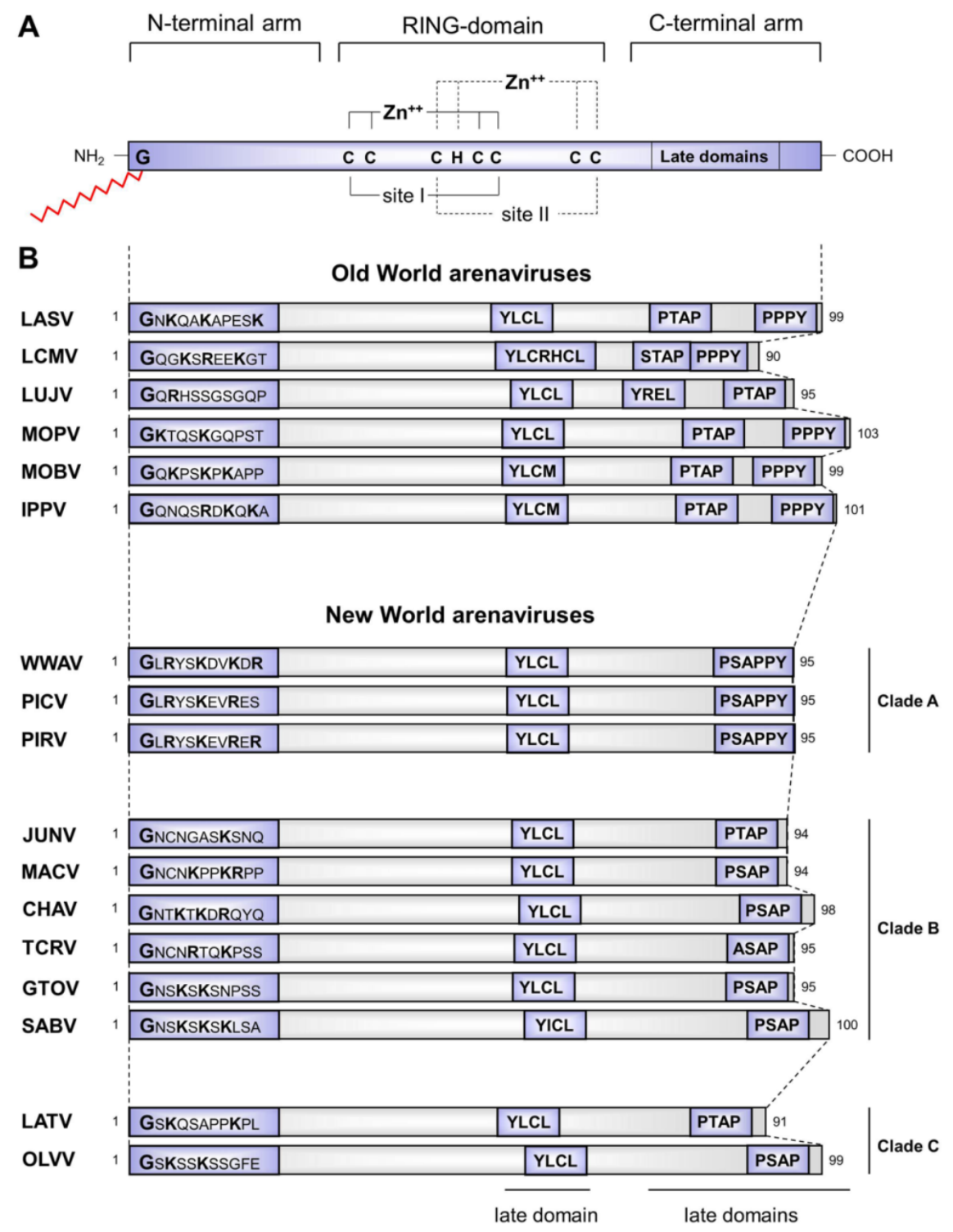




\subsection{Structural aspects of the distinct functional properties of $Z$ proteins}

While the $\mathrm{Z}$ proteins of different arenaviruses vary in their amino acid sequence and length and, in part, their biological functions, they all share distinct structural features and motifs that play important roles in mediating their multifunctional activities. Common characteristics conserved among OW and NW arenavirus $\mathrm{Z}$ proteins include an N-terminal myristoylation signal, a central RING domain and small tetra-peptide motifs that function as viral late domains located in the C-terminal arm (Fig. 4A).

$\mathrm{N}$-terminal myristoylation is an irreversible, co-translational protein modification during which myristate (a 14-carbon fatty acid) is covalently attached to an N-terminal glycine, catalyzed by the host cell enzyme N-myristoyl transferase using myristoyl-CoA as a substrate upon removal of the initiator methionine by a methionine aminopeptidase [69]. Generally, known functions of the myristyl group include membrane targeting and binding of proteins, enabling protein-protein interaction and providing both the structural basis and conformational stability for the assembly of protein complexes on membranes. N-terminal myristoylation is also a conserved feature of all arenavirus $\mathrm{Z}$ proteins that is required for their biological functions [70,71]. The myristyl moiety facilitates $Z$ membrane anchoring and intracellular targeting, $Z$ self-assembly, and interaction of $Z$ with other arenavirus proteins [7173]. Consequently, treatment with myristic acid analogs leads to dose-dependent inhibition of Zmediated release of VLPs and significantly reduces infectious virus particle production of several OW and NW arenaviruses [70,71,74]. Although the importance of $\mathrm{N}$-myristoylation in $\mathrm{Z}$ protein function is well documented, the molecular mechanism(s) by which the myristate acts within the various $Z$ functions is not yet fully understood. Notably, in addition to the N-terminal myristoylation signal, several arenavirus $Z$ proteins contain clusters of basic residues near their N-termini (Fig. 4B). As shown for the transforming protein pp60v-src of Rous sarcoma virus, such basic amino acids that are located close to the myristoylation site are required for efficient membrane binding [75]. However, the question of whether $\mathrm{N}$-terminally located basic residues of $\mathrm{Z}$ contribute to its membrane association remains to be investigated. Interestingly, structural studies of LASV Z revealed that both the myristoylation signal and the adjacent basic residues are located within a structurally disordered region of $Z$ termed the N-terminal arm (residues 1-29) [76]. This N-terminal arm is highly flexible, thus potentially enabling the basic residues to associate with acidic phospholipids in cellular membranes, which could result in enhanced membrane association of $\mathrm{Z}$.

RING domains are distinct structural motifs that can be found in many different cellular and viral proteins. They range in length from 40 to 60 amino acids and are structurally well ordered, typically consisting of a single $\alpha$-helix and multiple $\beta$-sheets. Their most prominent feature is the conserved $\mathrm{Cys}_{3} \mathrm{HiSCys}_{4}$ amino acid motif, through which they coordinate two zinc cations. With a length of $\sim 60$ amino acids and a central $\mathrm{Cys}_{3} \mathrm{HisCys}_{4}$ motif, the highly conserved RING domain of arenavirus $\mathrm{Z}$ protein displays all the characteristic features of RING domains (Fig. 4A). Structural studies of LASV $\mathrm{Z}$ protein revealed that the zinc coordination sites, referred to as site I and II, are located on opposing sides of the RING domain [76]. This arrangement generates structurally different surfaces through which the RING domain is thought to act as a platform for the interaction of $Z$ with its various viral and cellular binding partners. While the arrangement of amino acids around site $I$ is very similar to the structure of known RING domains, the conformation around site II is a characteristic feature currently exclusive to arenavirus $\mathrm{Z}$ proteins [76]. It is currently unknown whether this conformation is the basis 
for some of Z's unique features. The RING domain (particularly site I) has also been shown to be highly important for correct $Z$ self-assembly, as exemplified by the ability of an isolated LCMV RING domain to form spherical structures in vitro [77-79]. Such RING domain-mediated super-molecular assembly enhances the biochemical activities of LCMV Z [78]. Whether similar structures are also formed by $Z$ in infected cells remains elusive. $Z$ induces dot-like structures in the cytoplasm of both infected and transfected cells, which are comparable in their dimensions to the structures formed by recombinantly expressed $\mathrm{Z}$ protein isolated from bacterial systems. However, due to the lack of detailed structural information of these intracellular assemblies it remains unknown whether they are identical to the spherical structures formed by $\mathrm{Z}$ during recombinant protein expression in bacteria.

Late domains are small tetrapeptide motifs that have been identified in the matrix proteins of various enveloped RNA viruses and in the Gag proteins of a number of retroviruses. They consist of the amino acid sequences $\mathrm{P}[\mathrm{T} / \mathrm{S}] \mathrm{AP}, \mathrm{PPxY}$, or YxxL, where ' $\mathrm{x}$ ' represents any amino acid (reviewed in [80]). Late domains mediate protein-protein interactions between viral proteins and components of the endosomal sorting complexes required for transport (ESCRT), which mainly constitute the vacuolar protein sorting (VPS) pathway [80]. Both OW and NW arenavirus species contain a highly conserved YxxL motif located within the central RING domain. Furthermore, all arenavirus $Z$ proteins carry P[T/S]AP- and PPPY-type late domains in their C-terminal parts. However, these vary greatly between OW and NW virus species both in their number as well as their relative position (Fig. 4B). The $Z$ protein from OW LCMV harbors a PPPY motif and a P[T/S]AP-like domain STAP, while Z proteins from African arenavirus species carry closely spaced a PPPY and a classical PTAP motif. However, the $\mathrm{Z}$ protein of the newly discovered OW LUJV is an exception to this rule, and sequence analysis has revealed an additional YxxL motif in place of the otherwise typical PPPY motif. Most NW arenavirus $Z$ proteins contain a P[T/S]AP motif at their C-terminal end. However, TCRV Z shows an ASAP motif at this position. Interestingly, $Z$ proteins from Pichinde virus (PICV), Pirital virus (PIRV), and WWAV possess overlapping PSAP and APPY (a potential PPPY-like late domain) tetrapeptide motifs that share some similarities to the overlapping late domains described for the Ebola virus (EBOV) matrix protein VP40 (PTAPPEY). Notably, the NMR-structure of LASV Z has shown that the C-terminal arm harboring these late domains is very similar to the N-terminal arm in that it, too, is structurally unordered and highly flexible. This flexibility is thought to enable LASV Z to exhibit varying conformational states, thereby allowing the C-terminal arm of LASV $Z$ to mediate interaction with different cellular binding partners through its late domains [81].

In summary, the arenavirus $\mathrm{Z}$ protein contains several distinct domains and conserved motifs which, together with its high conformational flexibility, allow $\mathrm{Z}$ to interact with various different cellular and viral binding partners.

\section{$3.2 \mathrm{Z}$ protein as a regulator of virus replication and transcription}

Early studies based on immunodepletion of $Z$ proteins from TCRV-infected cell extracts indicated that $\mathrm{Z}$ is required for both mRNA synthesis and genome replication [82]. In contrast to these observations, more recent studies using a TCRV minigenome system suggest that $Z$ protein is nonessential for transcription and replication of the viral genome. In fact, co-expression of $Z$ revealed an inhibitory effect on both transcription and replication of the minigenome [68]. Similar results have 
been observed using a LCMV reverse genetic system, wherein $\mathrm{Z}$ was not required for transcription and replication of the LCMV minigenome, but strongly inhibited LCMV minigenome expression in a dose-dependent manner [83]. This negative regulatory role of $Z$ is further supported by the observation that cells that transiently express $Z$ exhibit a significantly decreased susceptibility to infection with LCMV [83], while cells transduced with a recombinant adenovirus that express $Z$ are resistant to infection with LCMV and LASV [84]. Importantly, Z-mediated resistance to superinfection is not due to blocked virus entry, but rather to the strong inhibitory effect of $Z$ on virus polymerase activity, which leads to decreased production of infectious viral particles.

Initial clues to the molecular mechanism that $\mathrm{Z}$ uses to inhibit the transcription and replication arose from the observation that the TCRV Z protein directly interacts with the L protein (Fig. 5) [85], raising the possibility that this interaction might negatively regulate L-driven replication and transcription. L consists of four putative domains [86-88], two of which (in the case of TCRV L) have been shown to be binding sites for the $\mathrm{Z}$ protein. One binding site was mapped to the $\mathrm{N}$-terminus of $\mathrm{L}$, located between residues 156 and 292. A second binding site was identified within the RNA polymerase domain [87]. Residues within the $\mathrm{Z}$ protein that are presumably involved in L binding have been identified by assessing the ability of various $Z$ mutants to inhibit viral RNA synthesis. The inhibitory activity of LCMV and LASV Z requires an intact RING domain, whereas the N- and Cterminal residues are not essential for this function $[73,89]$. In particular, the $\mathrm{Zn}^{++}$-coordinating residues and a highly conserved tryptophan residue within the RING domain are essential for the strong inhibitory activity of Z on RNA synthesis [90]. Furthermore, in the case of TCRV Z, distinct residues located around the $\mathrm{Zn}^{++}$-coordinating amino acids have been shown to participate in the direct interaction with the polymerase [73]. Since the L protein still retains its RNA binding properties while associated to $\mathrm{Z}$, the interaction between both proteins is further thought to be important for the process of packaging viral RNA segments into progeny virions during assembly. Additionally, recent studies demonstrated that this direct interaction with $\mathrm{L}$ enables $\mathrm{Z}$ to inhibit the catalytic activity of the polymerase, thereby rendering it unable to perform viral RNA synthesis [91]. Further to this point, $Z$ may be involved in condensing the nucleocapsid via interaction with NP, thus leading to inhibition of the biosynthetic processes directed by the virus polymerase, as has been shown for matrix proteins of other negative-strand RNA viruses [92-94].

\subsection{The multifunctional activities of the $Z$ protein in virus assembly and budding}

\subsubsection{The role of the $\mathrm{Z}$ protein in glycoprotein GP incorporation}

To ensure the recruitment of RNPs to specific areas of the plasma membrane in which GP spikes are concentrated, the production of infectious particles requires a highly organized and wellcoordinated process of viral protein-protein interactions during assembly. Since the glycoprotein complex mediates both target cell binding and the subsequent fusion of the viral and host cell membranes during entry, the incorporation of GP into budding particles is essential for facilitating continued infection. The arenavirus glycoprotein is synthesized as an inactive precursor preGP-C that is co-translationally cleaved by signal peptidase into GP-C and the stable signal peptide (SSP) $[95,96]$. Post-translational maturation cleavage of GP-C by the host cell proprotein convertase S1P (site 1 
protease), also known as SKI-1 (subtilisin kexin isozyme-1), then leads to the generation of the distal receptor-binding subunit GP-1 and the transmembrane-spanning fusion competent subunit GP-2 [97100]. Since only cleaved subunits are incorporated into budding virions, proteolytic processing of GP$\mathrm{C}$ by S1P is absolutely necessary for the production of infectious particles [98]. Remarkably, the SSP is not only essential for S1P-mediated activation cleavage of GP-C by functioning as a trans-acting maturation factor [101], but remains stably associated with GP, primarily through interaction with a zinc-binding domain present in the cytoplasmic tail of GP-2 [102-104]. Together with GP-1 and GP-2, SSP forms the tripartite glycoprotein spike complex on the viral surface, making the mature glycoprotein spikes of arenaviruses unique among enveloped single-stranded RNA viruses [50,105].

Figure 5. Interaction of $\mathrm{Z}$ protein with other arenavirus proteins. The $\mathrm{Z}$ protein (blue) coordinates multiple interactions with other viral proteins. $Z$ protein associates with the viral glycoprotein GP (red) through interaction with the stable signal peptide (SSP) of GP. Interaction is dependent on $\mathrm{Z}$ myristoylation. Through amino acids located within and adjacent to the RING domain, $Z$ directly interacts with the C-terminal domain of nucleoprotein NP (light green). Interaction between $\mathrm{Z}$ and the viral polymerase L (orange) is facilitated by amino acids within the Z RING motif. Z contact sites within L have been mapped to its N-Terminus and the polymerase domain, although the exact locations of the binding sites remain to be determined. The schematic drawing of the polymerase $\mathrm{L}$ ultrastructure has been adopted from [86].

\section{Interaction of $Z$ protein with}

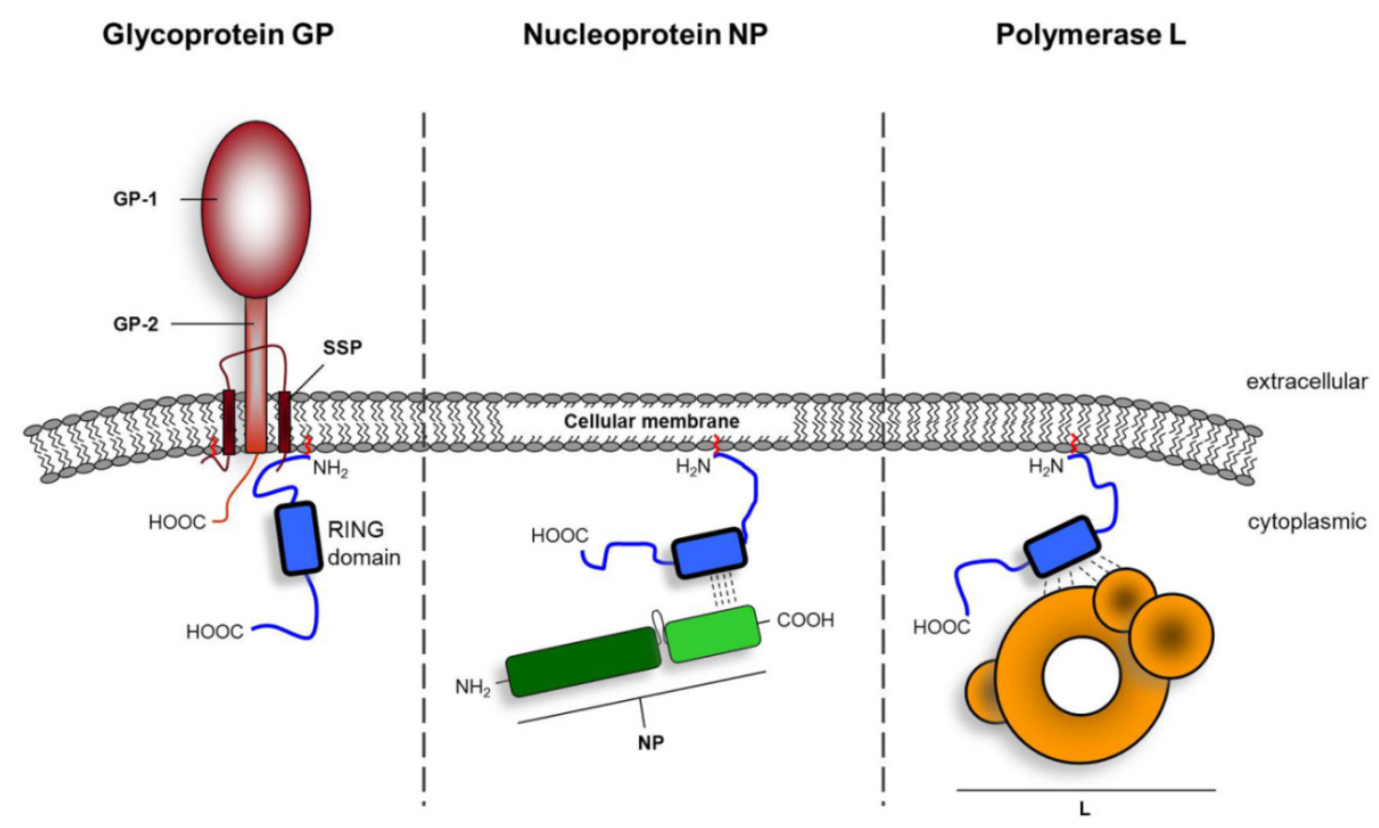

In spite of the progress made in understanding the structural details of arenavirus glycoproteins, the intracellular trafficking pathway and the maturation of GP, the mechanism by which the tripartite mature GP complex is incorporated into the lipid bilayer of the nascent virions during virus assembly is still only partially understood. The $\mathrm{Z}$ protein has been implicated in this process based on observed 
intracellular interaction between GP and Z (Fig. 5) [72,106]. GP and Z are also capable of interacting in VLPs [106], which coincides with their structural organization in arenavirus particles as observed using cryo-electron microscopy [51]. The N-terminal myristoylation of $\mathrm{Z}$ is critical for GP-Z interaction, whereas both the RING domain and the C-terminal late domains are non-essential for GP$\mathrm{Z}$ association [72]. Interestingly, $\mathrm{Z}$ directly associates with SSP, even in the absence of other subunits of the GP complex [72]. However, the molecular nature of the SSP-Z interaction still remains to be determined. The identification of the protein-protein interaction motifs within SSP and the Z protein will thus provide further insight into the mechanism underlying the incorporation of GP into nascent virions. In particular, defining the precise role of $\mathrm{N}$-myristoylation of $\mathrm{Z}$ in this process will be of great interest, as myristoylation of $\mathrm{Z}$ has been linked to various biological functions, including intracellular targeting [71]. Suppression of $Z$ myristoylation - either by mutation of the conserved glycine residue at position 2 (Z-G2A), or by treatment of wild-type $Z$ protein expressing cells with myristic acid analogs - adversely affected the subcellular localization of $Z$, altering it from a characteristic punctuate cytoplasmic distribution pattern to a more diffuse and predominant perinuclear accumulation [71]. In addition, N-myristoylation has been reported to have a strong impact on protein structure [107]. Further studies are therefore required to elucidate whether the limited association observed between GP and Z-G2A is due to altered intracellular localization or to structural changes of mutant $\mathrm{Z}$ that perturb efficient GP- $Z$ interaction.

Association of $Z$ with GP determines directed LASV release from polarized epithelial cells. In dissecting the viral determinants responsible for polarized virus budding, individually expressed $Z$ protein was shown to induce VLP budding from both apical and basolateral surfaces, whereas the addition of GP shifted VLP release to the apical plasma membrane [106]. Accordingly, infectious LASV buds from the apical membranes of polarized kidney cells [106].

It is well established that arenavirus particles assemble at the plasma membrane, therefore virion morphogenesis requires GP-Z co-localization at the site of virus budding. However, neither confocal microscopy [106] nor dual-label immuno-gold staining and electron microscopy [108] produced observable GP-Z association at the plasma membrane. Instead, co-localization between these two proteins was observed in vesicle-like structures in the cytoplasm near the nucleus [106], suggesting the potential existence of an intracellular co-trafficking mechanism to virus assembly sites. Although specific viral assembly pathways remain elusive for arenaviruses, data from our laboratory indicate involvement of late endosomal compartments as a trafficking intermediate for LASV Z protein (S.K. Fehling and T. Strecker, unpublished data). Interestingly, for Marburg virus (MARV), a member of the filovirus family, it has been previously reported that the matrix protein VP40 actively recruits the envelope glycoprotein GP to VP40-enriched late endosomal compartments. Accumulation of MARV GP and VP40 in this compartment is assumed to play an important role in the formation of the filoviral envelope and subsequent release of infectious MARV at the plasma membrane [109,110]. It will be interesting to assess whether distantly related arena- and filoviruses share similarities with respect to their intracellular assembly pathways.

In summary, the collaboration between GP and Z is critical for the production of infectious particles, although the signals and underlying mechanisms for incorporation of glycoprotein spikes into Z-driven virions during assembly remain to be identified.

\subsubsection{The role of $Z$ protein in RNP packaging}


Due to the bi-segmented nature of the arenavirus genome, a highly coordinated and selective packaging mechanism has to ensure that infectious progeny virions contain at least one of each genome segment during assembly. Arenavirus replication takes place in the cytoplasm of infected cells. Cell cultures infected with LASV and other arenaviruses typically reveal distinctive intracytoplasmic electron-dense viral inclusions that are suggested to be important sites for RNA replication (Fig. 6) [111,112]. Thus, the RNP complex not only has to be recruited from these cytoplasmic locations to virus budding sites at the plasma membrane, but also requires tethering to budding membranes in order to be incorporated into nascent virions. Early studies using chemical crosslinking have shown that LCMV Z is associated with the viral nucleocapsid in purified particles [53], suggesting that $Z$ is also involved in these processes. Since the RNP complex is composed of NP, L, and genomic RNA, each of these three components could, in principle, harbor the interaction sites that are important for Z-driven RNP packaging. For many other negative-stranded RNA viruses, such as EBOV, interaction between the matrix protein and the nucleoprotein is crucial for nucleocapsid incorporation into nascent virions [113]. Indeed, initial evidence for direct Z-NP interaction in the absence of other viral proteins has already been demonstrated for LASV (Fig. 5) [54]. Follow-up studies showed that the intracellular collaboration of NP and $Z$ leads to the incorporation of NP into LASV Z-induced VLPs [106]. Similar findings have been described for NW JUNV and TCRV, as well as for OW LCMV and MOPV [114-118], suggesting that NP-Z association is conserved within the Arenaviridae family. Collectively, these data indicate that interaction of NP with $\mathrm{Z}$ is important for RNP incorporation during virus assembly. Although recent studies have greatly improved our knowledge of the molecular basis for NP-Z interaction, precise details still remain to be determined. Structural studies of LASV NP and functional analysis of NPs from LASV, LCMV, and TCRV have shown that NP consists of two domains [115,116,119,120]. The N-terminal domain is involved in RNA binding and oligomerization [116,121,122], while the C-terminal domain of NP facilitates type I IFN antagonism [115,119,120,123], oligomerization [121], and association with $Z$ [114-116]. Interaction between NP and Z requires an intact RING domain of Z, as it has been shown that mutations of the RING structure drastically affected Z-NP interactions and the ability of JUNV Z to incorporate TCRV NP into budding VLPs [118]. However, future studies are necessary to elucidate whether the functional or structural integrity of the RING domain is of critical importance for the reported observations regarding the role of the RING domain in Z-mediated incorporation of NP into VLPs. Also, mutation of residue L79 to alanine within JUNV Z protein severely impaired intracellular Z-NP interactions and the incorporation of NP into VLPs, resulting in decreased VLP infectivity [118]. This observation has been extended to LASV, since mutation of the corresponding amino acid L71 within LASV Z protein similarly affected the infectivity of recombinant VLPs, supporting the role for $Z$ in the packaging of RNPs into mature infectious virions [89]. Interestingly, for MOPV it has been implied that the host cell protein Alix/AIP1 (ALG-2-interacting protein 1) directly participates in Z-NP interaction, presumably by bridging both proteins [124]. 
Figure 6. Viral inclusions in LASV-infected cells. Ultrathin sections of LASV-infected Vero cells. Electron micrographs show viral inclusions (arrow) (A) near mitochondria (MT) or (B) near multivesicular bodies (MVB). Bars, 250nm.

A

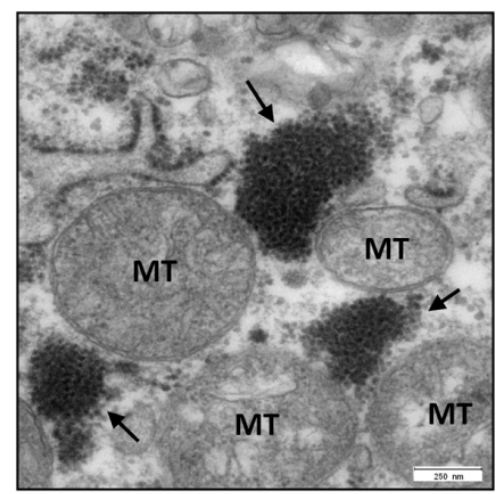

B

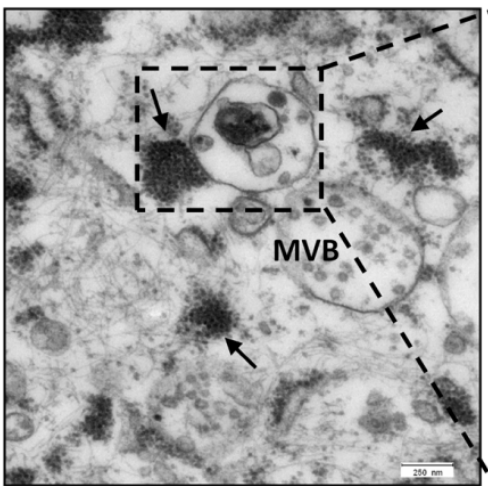

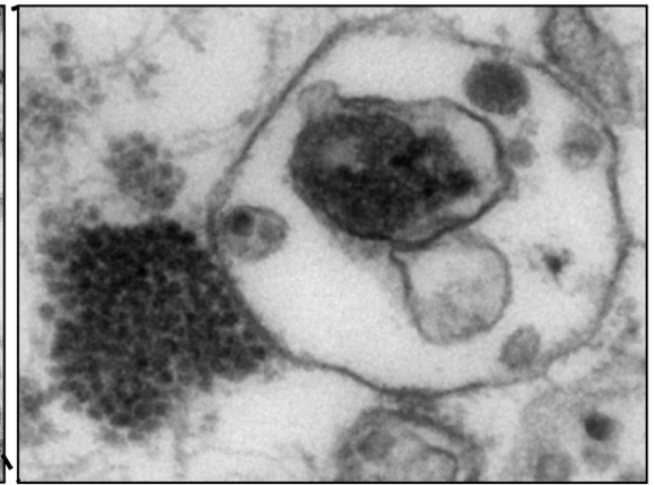

Although the interaction between NP and Z plays a central role in genome packaging, additional mechanism(s) for RNP incorporation may exist. Recent studies have demonstrated that the $\mathrm{Z}$ protein also binds to the polymerase L, leading to the formation of Z-L heterodimers [85,91]. While the association between $\mathrm{Z}$ and $\mathrm{L}$ has been shown to play an important role in regulating viral genome replication and transcription, a recent study by Kranzusch and colleagues suggests that Z-L interaction plays a direct role in ensuring the packaging of the viral polymerase as part of the functional RNP complex [91]. This is particularly important for arenaviruses, since the viral genome per se is not infectious, making polymerase packaging crucial to the production of infectious particles. Interaction with $\mathrm{Z}$ renders the polymerase catalytically inactive. Importantly, interaction with $\mathrm{Z}$ does not prevent $\mathrm{L}$ from binding to viral RNA, as demonstrated by the ability of the Z-L complex to bind to viral promotor sequences [91]. Instead, interaction with $\mathrm{Z}$ prevents the early steps of RNA synthesis initiation, therefore keeping the polymerase locked and bound to viral promotor sequences, and hence associated with the viral RNPs. In addition, in vitro studies have demonstrated that $Z$ is able to inhibit on-going RNA synthesis, indicating that $\mathrm{Z}$ can also contact $\mathrm{L}$ during active replication and/or transcription of the viral genome [91]. Whether $Z$ ensures polymerase packaging by interaction of $L$ in the context of a functionally active RNP or whether $\mathrm{Z}$ forms a heterodimeric complex with L, which subsequently associates with RNPs through interaction with the viral RNA, remains to be determined.

The matrix proteins of several different RNA virus families, such as bornaviruses, orthomyxoviruses, rhabdoviruses and retroviruses, possess RNA binding capacities, which may have implications for the incorporation mechanism of RNPs into the membrane envelope during budding [92,125-127]. The arenavirus $\mathrm{Z}$ protein largely binds to nucleocaspids through its interaction with NP, and since the arenavirus NP and L protein are larger and more positively charged than the NP and $\mathrm{L}$ of other negative-strand viruses, it is likely that they function as the major RNA-binding proteins. The $\mathrm{Z}$ protein central RING domain is a globular type of zinc-binding domains that more frequently binds other proteins, in contrast to zinc-finger domains which are known for intercalating into nucleic acids [128].Though, the potential RNA binding activities of Z remain to be established. 
Similarly, knowledge of the mechanism underlying intracellular RNP delivery to viral budding zones remains elusive. The functional relationships between $\mathrm{Z}$ and NP or $\mathrm{Z}$ and $\mathrm{L}$ suggest a potential co-trafficking process of the RNP complex via Z trafficking pathways. Consistent with this assumption, the co-expression of $\mathrm{Z}$ leads to a redistribution of NP to Z-positive dot-like structures, while solitary expressed NP is evenly distributed in the cytoplasm. Z-NP co-localization was observed either at the plasma membrane, as shown for TCRV [116,118], or within cytoplasmic patches, as documented for LASV, LCMV and MOPV [54,106,114,115]. In contrast, GP seems not to be involved in RNP trafficking since neither a direct interaction nor intracellular co-localization between GP and NP has been detected, which is consistent with the observation that NP is not incorporated into VLPs generated by solitary expression of GP [106]. Co-localization of both proteins in distinct perinuclear clusters was only observed in cells additionally expressing $Z$ protein [106]. Taken together, these observations led to the idea that $Z$ serves as a 'bridge' between GP and NP, and therefore links the viral envelope and viral RNP complexes, making $Z$ a key mediator in virus assembly processes. Cryo-electron microscopy of viral particles confirmed that $Z$ is tightly associated with GP and NP, forming a dense layer between both proteins [51]. In a heterologous VLP system using chimeric JUNV/TCRV, the co-expression of TCRV NP greatly enhanced the incorporation of JUNV GP into JUNV Z-induced VLPs, indicating that $\mathrm{Z}$ regulates incorporation of GP into nascent virions through interaction with NP [118]. However, when viral protein recruitment was examined in the homologous context, a significant increase in GP incorporation into Z VLPs in the presence of NP was observed neither for NW JUNV and TCRV nor OW LASV [106,117].

Altogether, Z protein is a key regulator of virus assembly. Through its interaction with GP, NP and $\mathrm{L}$, the $\mathrm{Z}$ protein ensures the incorporation of viral RNP complexes into budding particles that contain glycoprotein spikes, leading to the release of infectious virions.

\subsubsection{Z-mediated recruitment of host cell proteins essential for virus budding}

Arenaviruses exit their host cells by budding from the plasma membrane (Fig. 7A). The final steps prior to virus release involve the envelopment of the viral nucleocapsid by the host cell-derived lipid membrane that harbours mature GP spikes, followed by a subsequent membrane fission event during which the nascent virion is separated from the host cell membrane. $Z$ protein is the key player in these processes. On the one hand, the $\mathrm{Z}$ protein mediates all of the essential virion assembly events that ensure the packaging of all viral components required for infectivity, while on the other hand, $Z$ protein alone facilitates virus-host protein-protein interactions that are necessary but also sufficient to create particles (Fig. 7B). This assumption is based on the observation that solitary expression of $\mathrm{Z}$ protein leads to the formation and release of lipid-enveloped, morphologically regular VLPs at the plasma membrane $[52,54,129]$. This self-budding activity has been linked to the late domains (Fig. 4B) $[52,130]$. The functional integrity of the late domains is of critical importance for the LASV and LCMV Z-driven release of enveloped particles, since disruption of these motifs abrogated efficient VLP production [52,130]. 
Figure 7. Assembly and budding of arenaviruses. (A) Ultrathin sections of LASV-infected Vero cells. The left image shows an electron microscopic picture of LASV budding from the surface of infected cells. Discrete area of membrane thickening and membrane curvature at the left indicates an early stage of virus budding, while the particle shown at the right almost fully assembled. Bar, 100nm. The electron microscopic image shown on the right demonstrates $\mathrm{Z}$ protein-specific immuno-gold labeling (10nm gold particles) at LASV budding sites at the plasma membrane. Bar, 50nm. (B) Model for arenavirus assembly and budding. $\mathrm{Z}$ protein (blue) is the key regulator of virus assembly. Through interaction with GP (red), NP (light and dark green) and L (orange), the Z protein mediates the incorporation of viral RNP complexes into GP-spike containing particles, leading the release of infectious virions from the plasma membrane of infected cells. Viral late domains encoded by $Z$ facilitate interaction with Tsg101 and Nedd4, thereby presumably recruiting other components of the cellular ESCRT machinery. The AAA-ATPase Vps4 is required for efficient budding of arenavirus virions.

A
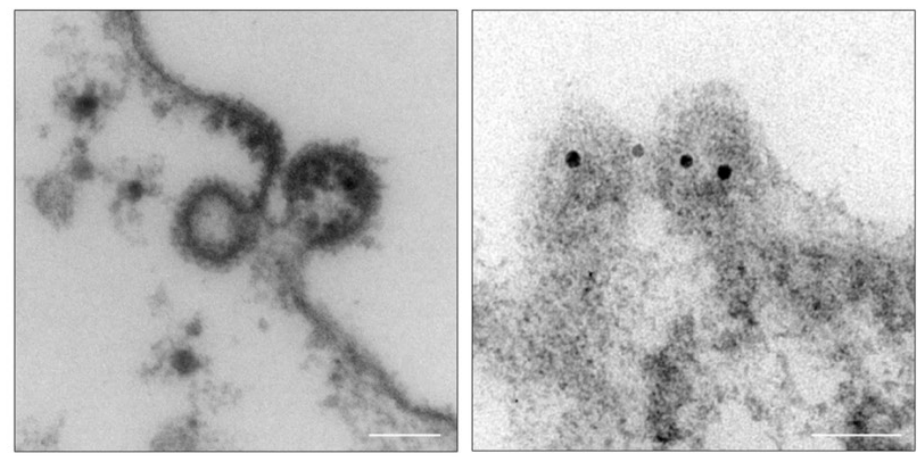

B

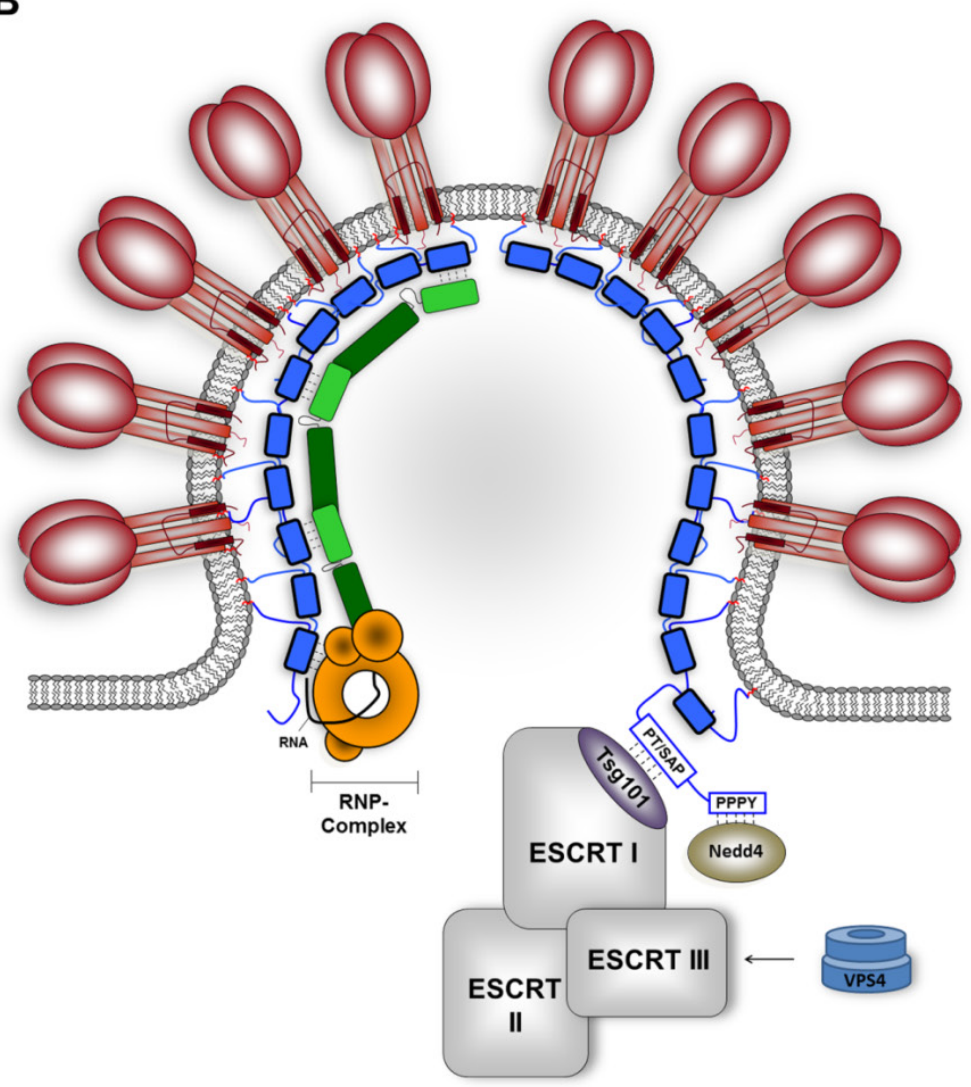


Viral late domains are highly conserved motifs and have been found within viral matrix proteins of numerous enveloped RNA viruses, including rhabdoviruses, filoviruses, and paramyxoviruses as well as within the Gag proteins of various retroviruses (reviewed in [80,131]). Through interaction with individual proteins of the cellular ESCRT complexes, they facilitate the recruitment of the VPS machinery to virus budding sites. The VPS pathway normally functions in the downregulation of cell surface receptors and their sequestering into MVBs, which subsequently deliver their intraluminal cargo for lysosomal degradation. Notably, the sorting of protein cargo into the lumen of the MVB occurs by a vesicular budding event that is catalyzed by the coordinated action of the ESCRT complexes [132,133]. The ESCRT machinery comprises the four multiprotein complexes, ESCRT-0, ESCRT-I, ESCRT-II, ESCRT-III, as well as several ESCRT-associated factors that include Alix/AIP1 and the AAA-ATPase Vps4. ESCRT-0 plays a role in recruitment of ubiquitinated cargos and their concentration at the endosomal membrane. ESCRT-I and II cooperate to induce membrane bud formation and confine cargo, while the ESCRT-III protein complex causes membrane scission that results in the release of vesicles into MVBs [134]. Finally, Vps4 plays an essential role in the completion of vesicle formation by disassembling ESCRT-III components from the target membrane. Because both processes are directed away from the cytosol, ESCRT-driven budding of vesicles into the lumen of the MVB topologically resembles the budding of enveloped particles from the plasma membrane (reviewed in [135-137]). It is therefore not surprising that viruses recruit the cellular ESCRT machinery to organize budding of viral progeny, mediated through their late domains. Viral proteins that encode $\mathrm{P}[\mathrm{T} / \mathrm{S}] \mathrm{AP}$ late domains gain access to the ESCRT pathway through interaction with the ESCRT-I component Tsg101 (tumor susceptibility gene 101) [138-140], while the YxxL motif mediates binding to Alix/AIP1, which is an ESCRT-I and III binding partner [141-143]. The PPXY late domain motif has been linked to interactions with various members of the family of mammalian Nedd4 (Neuronal precursor cell-expressed developmentally downregulated 4) E3 ubiquitin ligases (hereafter called Nedd4-like proteins) [144-150].

Tsg101 has been reported to be involved in LCMV and LASV budding. Perturbing Tsg101 function by RNA interference resulted in decreased levels of both LASV and LCMV Z-mediated budding $[129,130]$. However, the mechanism by which Tsg101 is recruited to virus budding sites is not fully understood. Particularly in the case of LCMV it will be of interest to elucidate the molecular relationship between $Z$ protein and Tsg101, since Z lacks the classical Tsg101-binding motif PTAP. Direct interaction between Tsg101 and $Z$ protein has not yet been established and it remains to be determined whether the late domains within $Z$ play a role in this process. To investigate Z-Tsg101 interaction, wild-type LASV Z protein or Z mutants with individually disrupted PTAP and PPPY late domains were tested for binding to Tsg101 in a co-immunoprecipitation assay. Wild-type $Z$ protein is efficiently co-precipitated with Tsg101 following recombinant expression in human embryonic kidney 293 T cells (Fig. 8A and B). Mutation of the PTAP motif (ATAA) resulted in a decreased ability of Z to interact with Tsg101, demonstrating that - in the case of LASV - the PTAP motif contributes to, but is not the sole determinant of Z-Tsg101 binding. Remarkably, the PPPY motif appears to be very important for interaction with Tsg101. Mutation of PPPY to PPPA (which has been shown to be sufficient to block VLP release just as effectively as a PPPY deletion mutant [52]) completely eliminated the association between LASV Z and Tsg101 (Fig. 8B). Consistent with these observations, the PPPY motif plays a dominant role in Z-mediated budding, whereas the effects of mutating the 
PTAP late domain were much less severe [52]. A very similar observation has been made for the interaction of Tsg101 with the MARV matrix protein VP40, which was reported to be dependent on the presence of a functional PPPY motif [151]. In contrast, mutations of the PPPY motif within the Gag protein of human T-cell leukemia virus type 1 (HTLV-1) had no effect on its ability to bind Tsg101 [152], suggesting that various viruses have evolved different mechanisms for recruiting Tsg101.

Figure 8. Interaction of LASV Z protein with Tsg101 and Nedd4. (A) Wild-type Z protein and substitution mutants used in this study are shown schematically. Coimmunoprecipitation analysis of LASV Z protein and Tsg101 (B) or Nedd4 (C). 293T cells were co-transfected with plasmids encoding the indicated $Z$ constructs and Tsg101 or Nedd4. For studies with Nedd4, we used the WW modules (protein-protein interaction domains containing two conserved tryptophan residues) 2-4 of Nedd4 that have been shown to be sufficient for interaction with the EBOV VP40 [194]. At 48h posttransfection, cells were lysed and Tsg101 or Nedd4 were precipitated using proteinspecific antibodies. Co-precipitated Z protein was detected by SDS-PAGE with subsequent immunoblotting using a Z-specific antibody. (D) Tsg101 and Nedd4 are recruited into Zinduced VLPs. Electron micrographs show Z-driven VLPs that were immunostained for incorporated Tsg101 (left panel, 5nm gold particle, arrows) and Nedd4 (right panel, 5nm gold particle, arrows). Z protein was specifically stained using antibodies coupled to $10 \mathrm{~nm}$ gold particles. Bars, 100nm.

A

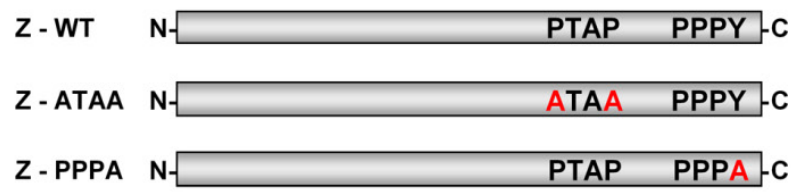

B

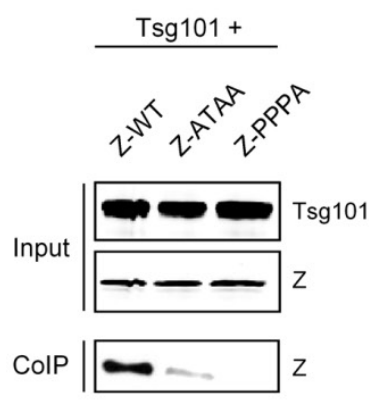

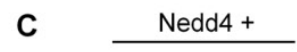

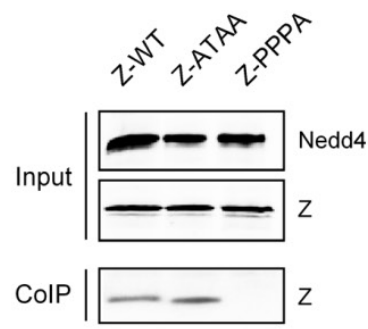

D

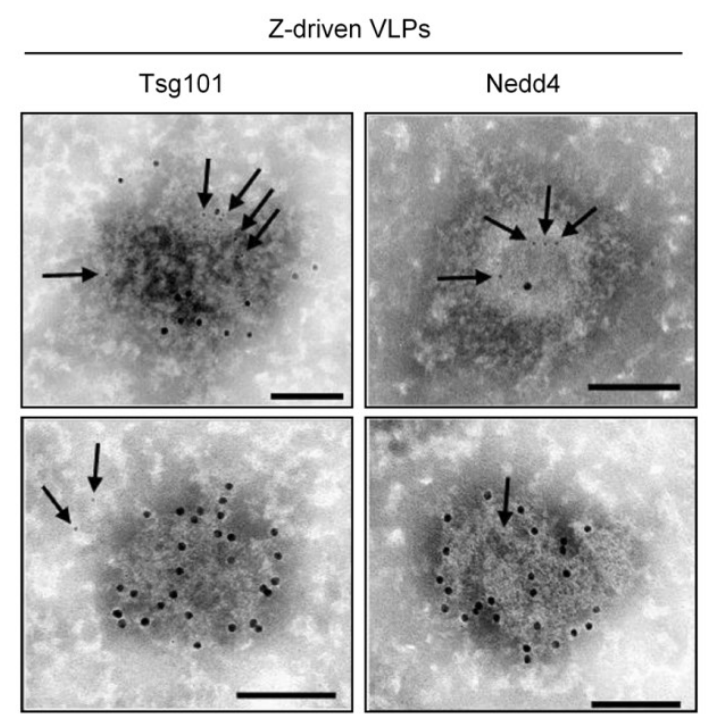

Because Nedd4 and Nedd4-like proteins have been implicated as critical host factors for PPxY motif-dependent budding, the requirement of a functional PPPY motif indicates that upstream ubiquitin ligase activity may be necessary before $Z$ protein recruits Tsg101. Nedd4 and Nedd4-like ubiquitin ligases are part of an ubiquitination enzyme cascade that involves an ubiquitin-activating enzyme E1 and an ubiquitin-conjugating enzyme E2. The final step mediated by E3 ubiquitin ligases 
results in the covalent attachment of ubiquitin to target proteins. Ubiquitination often plays a central role in recruitment of proteins by the ESCRT machinery, which may explain also the link between ubiquitin ligases and virus budding [153,154]. The potential involvement of Nedd4 in Z-mediated budding is demonstrated by the observation that LASV Z protein efficiently binds to this host cell protein (Fig. 8C). Co-immunopreciptation studies also show that this interaction requires an intact PPPY motif, since the PPPA mutant failed in its ability to bind to Nedd4, while mutations of the PTAP motif have no effect of Z-Nedd4 interaction (Fig. 8C). In addition, several Nedd4-like proteins, including WWP1, WWP2, Itch, Smurfl, and Smurf2, are capable of interacting with Z protein (T. Strecker, unpublished data). These observations indicate that Nedd4 or Nedd4-like proteins may link the $\mathrm{Z}$ protein to the VPS pathway, although the exact contribution of the individual ubiquitin ligases in Z-mediated budding remains to be determined. However, previous work has shown that overexpression of a dominant-negative mutant of Nedd4 and depletion of Nedd4 by siRNA does not reduce LASV Z-driven VLP production [129]. Notably, human Nedd4 proteins exist in at least two principal isoforms designated Nedd4-1 and Nedd4-2, which are encoded by different genes [155]. Nedd4-1 (but not Nedd4-2) is recruited by HTLV-1 Gag and subsequently facilitates its ubiquitination [149]. More work will be necessary to elucidate the details of the specific role of individual Nedd4 proteins in arenavirus budding. The observation that LASV Z is physically able to interact with Nedd4 and Nedd4-like proteins raises the question of a potential role of ubiquitination of $\mathrm{Z}$ and its functional relevance in arenavirus budding. The $\mathrm{Z}$ protein of LASV exhibits multiple ubiquitinated forms in cells that also overexpress ubiquitin, indicating that $Z$ protein is a target for ubiquitination. Interestingly, a similar protein pattern of $Z$ was observed in cells that coexpress various Nedd4-like proteins (T. Strecker, unpublished data). Future studies will be aimed at understanding the precise function of ubiquitination in arenavirus budding.

The molecular details of how the Z-Tsg101 and Z-Nedd4 interactions promote virus budding from the plasma membrane are currently being elucidated in our laboratory. For LASV we propose a model in which Z interacts successively with Nedd4 and Tsg101. Both factors were efficiently incorporated into Z-specific VLPs, supporting the concept of their intracellular interaction (Fig. 8D). Interaction with Nedd4 is assumed to lead to ubiquitination of $Z$ and subsequent Tsg101-mediated recruitment of the ESCRT machinery, which then facilitates the budding of virus particles. Tsg101 not only interacts with PTAP late domain motifs, but also recognizes ubiquitin that is attached to proteins [156,157], which could explain the mechanism underlying the participation of Tsg101 in PPxY motif-dependent LCMV Z protein budding. TCRV Z protein buds from cells despite lacking the classical late domain motifs P[T/S]AP and PPxY and does not require Tsg101 activity [158]. Additionally, the potential late domain motifs ASAP and YLCL found in TCRV Z do not play a role in $Z$ self-budding activity $[117,158]$, indicating that TCRV $Z$ employs a budding mechanism distinct from that found in other arenaviruses. The differences in type and number of late domains within various $Z$ proteins are still not fully understood and it is not currently known whether the P[T/S]AP and PPxY motifs act in a redundant or synergistic way in arenaviruses in which both motifs are present. Similarly, further studies are required to address whether the individual late domains act in a cell type-dependent manner. For example, the PSAP motif within the matrix protein of vesicular stomatitis virus was recently reported to contribute to cell type-dependent virion egress [159]. The identification of cell type or host cell-species specific factors will be important to better understand the mechanisms that 
determine efficient arenavirus budding, and thus viral tropism. In spite of the mechanistic differences between the ways various arenaviruses utilize the cellular VPS pathway for virus budding by recruiting different components of the ESCRT machinery, they all share the requirement of Vps4 for the final release of virus particles from the host cell membrane $[129,158]$. Although many questions still remain unanswered, current results highlight the important role of $\mathrm{Z}$ protein in the final stage of arenavirus budding. In order to better understand the sequence of events that finally lead to the release of infectious arenavirus particles, one of the major future tasks is to identify the individual ESCRT components that are necessary and also sufficient to mediate the budding process.

\subsection{Z-mediated regulation of host cell functions}

During the viral recplication cycle, the $\mathrm{Z}$ proteins of several arenaviruses regulate key host cell functions and favor viral replication, predominantly through direct interaction with different cellular factors. Currently, known cellular factors include the promyelocytic leukemia protein (PML), the nuclear fraction of the ribosomal protein $\mathrm{P} 0$, the eukaryotic translation initiation factor 4E (eIF4E) and the proline-rich homeodomain protein (PRH).

PML is an important regulator of mammalian cell growth that forms nuclear bodies which are altered by some disease conditions including acute promyelocytic leukemia and viral infection [160]. In cells infected with LCMV, PML is relocalized from the nucleus to the cytoplasm where it forms large bodies with Z. Furthermore, LCMV and LASV Z proteins alone are sufficient to redistribute PML to the cytoplasm and form specific complexes in vitro, implying a direct interaction between these two proteins [161]. Potential functions of the association between $\mathrm{Z}$ and PML include evasion of host cell apoptosis (given that PML promotes apoptosis [162,163]), and evasion of the host cell immune response, since PML is assumed to play a role in antiviral defense [164,165].

Ribosomal P proteins (P0, P1 and P2) are essential parts of the large ribosomal subunit and are involved in many of the ribosomal functions, such as binding to $28 \mathrm{~S}$ RNA and association with eukaryotic elongation factors and aminoacyl tRNA. Studies of LCMV infected cells have shown that a distinct nuclear portion of $\mathrm{Z}$ colocalizes with ribosomal $\mathrm{P}$ proteins ( $\mathrm{P} 0, \mathrm{P} 1$, and $\mathrm{P} 2$ ), which are an essential part of the large ribosomal subunit [166]. However, in contrast to PML, the P proteins are not redistributed upon LCMV infection. Instead, the expression level of P1 and P2 are substantially downregulated. Since P1 and P2 are part of the ribosome, this Z-mediated down-regulation might perturb ribosomal function. In contrast, the level of P0 remains unchanged during infection. The nuclear fraction of P0 has been associated with translationally coupled DNA excision repair and with nonspecific endonuclease activity. Thus, P0 may be involved in the nucleic acid processing activities necessary for LCMV replication, which might explain why its expression level is not affected unlike $\mathrm{P} 1$ and P2. Interestingly, $\mathrm{Z}$ not only colocalizes, with but also binds directly to the nuclear fraction of P0. Consequently, P0 is also present in LCMV virions, which may explain why LCMV and other arenaviruses contain ribosomes within their virions [166]. However, the exact details of this potential Z-mediated incorporation of ribosomes and its possible functions in the viral life cycle remain unclear.

The eukaryotic translation initiation factor eIF4E is a key component of the cellular translation machinery. It facilitates the binding of ribosomes to the 5 cap structures of cellular mRNAs, hence promoting eIF4E-dependent protein translation [167]. LASV and LCMV Z proteins have been shown 
to interact with eIF4E. Through this interaction, $\mathrm{Z}$ selectively represses protein expression in both infected and transfected cells, and this is thought to favor the establishment of chronic infections [168]. Structural and biochemical studies have revealed that $Z$ does not affect eIF4E expression or stability, but binds directly to the cellular factor [79]. Through residues located within the first zinc-binding site of its RING domain, LASV Z contacts the dorsal surface of eIF4E and induces conformational changes in its distal surface, which itself harbors a cap binding site [76]. In turn, this significantly reduces the affinity of eIF4E for its natural substrate (i.e., cellular 5' cap structures), resulting in the specific reduction of protein synthesis dependent on eIF4E [168]. Interestingly, eIF4E-dependent proteins include factors involved in host cell innate immunity, such as IRF-7 (interferon regulatory factor 7), which is a key regulator of the type I IFN-dependent immune response. Therefore, the inhibition of eIF4E through $\mathrm{Z}$ may represent an additional mechanism evolved by arenaviruses to counteract the host IFN system (as discussed below).

In specific arenavirus-host contexts, the $Z$ protein may also influence virus replication and pathogenesis, through association with the host factor PRH, a cellular transcription factor involved in the early development of the brain, thyroid, and liver [169]. PRH is specifically expressed in liver cells during liver injury and plays a role in subsequent regeneration processes. By infecting human hepatic cells lines or rhesus macaques with the highly virulent strain LCMV-WE or the related avirulent strain LCMV-ARM, it was found that LCMV-WE infection of liver cells leads to drastic reduction of $\mathrm{PRH}$ expression, while the level of expression remains unaltered during infection with the avirulent LCMV-ARM [170]. This is particularly interesting, since LCMV-WE but not LCMV-ARM induces hepatocyte proliferation in infected rhesus macaques [171]. High virus titers are recovered from the liver of infected animals only upon challenge with LCMV-WE [171,172]. Down-regulation of PRH is thus thought to eliminate the antiproliferative effects of PRH and to promote liver cell division, thereby favoring virus replication while leading to pathogenesis by blocking the regeneration of liver cells. Biochemical studies revealed that the LCMV Z protein directly interacts with PRH through its RING domain [170,173], which is why $\mathrm{Z}$ is thought to play an important role in the downregulation of $\mathrm{PRH}$. However, whether this effect is mediated by $\mathrm{Z}$ alone, or whether additional viral proteins are involved in the process, is currently not known. Notably, the Z-PRH interaction may play a significant role in specific arenavirus-host contexts but it seems unlikely that it is a general mechanism by which arenavirus infection induces disease, since up-regulated liver proliferation is observed only in rhesus macaques infected with LCMV-WE. In contrast, mice infected with low doses of LCMV-WE showed no signs of liver damage [174].

In summary, the arenavirus $Z$ protein interacts with a variety of different cellular factors. Although the exact molecular details of some of the associations between $Z$ and these cellular factors are not fully understood, potential effects include evasion of host cell defense and apoptosis, inhibition of ribosomal functions, and selective repression of host cell protein expression. All these interactions may trigger or counteract a plethora of host cell reactions that favor efficient viral replication or the establishment of chronic infections. The involvement of $\mathrm{Z}$ protein in these diverse processes underscores the important role of $Z$ in the arenavirus life cycle. 


\subsection{New World arenavirus $Z$ proteins antagonize the host cell interferon system}

Many different viruses encode for antagonists of the type I IFN response in order to evade cellular immunity. Type I IFNs (IFN- $\alpha / \beta)$ are secreted mediators in vertebrate immune systems that induce an antiviral state in their target cells, thereby limiting virus replication and spread. With the exception of TCRV, all arenaviruses analyzed to date have been shown to inhibit the up-regulation and production of type I IFNs in cell culture to some extent [175-178]. Early studies on IFN production in LCMVinfected cells showed that this suppression is caused by a block in the activation of the latent transcription factor IFN regulatory factor 3 (IRF-3) [179]. In this study, NP was identified to be sufficient for inhibiting both nuclear translocation of IRF-3 and IFN production. Subsequent work has extended this finding to the NPs from the OW LASV arenavirus and the NW JUNV and MACV arenaviruses, while it was also shown that the TCRV NP is unable to inhibit IFN production [175]. Subsequently, it was found that the activity of NP as an IFN antagonist is based on its ability to digest double-stranded RNA [119,120,123], which is a potent inducer of IFN production. Additionally, different arenavirus NPs directly interact with IKKe (IкB-kinase epsilon), which is an essential component of the IRF-3 signaling pathway. NP-mediated blocking of IKK $\varepsilon$ activity inhibited downstream signaling, preventing induction of IFN production [180]. Taken together, these observations led to the notion that NP is the main arenavirus interferon antagonist.

Interestingly, in the case of NW arenaviruses, the $\mathrm{Z}$ protein also participates in the suppression of type I IFN production. While NP is supposed to interfere at various steps in the IFN induction cascade, the $\mathrm{Z}$ proteins of NW arenaviruses specifically interact with RIG-I (retinoic acid-inducible gene I product) [181], which has an essential function in double-stranded RNA-induced innate antiviral response. Upon RNA binding, RIG-I associates with its interaction partner MAVS (Mitochondrial AntiViral Signaling), leading to the activation of a signaling cascade which results in the nuclear translocation of IRF-3 and hence the production of IFN- $\beta$. Importantly, RIG-I has been shown to be involved in the up-regulation of type I IFN expression in response to transfection of cells with LCMV genomic RNA [182]. However, the interaction between RIG-I and Z disrupts the necessary complex formation between RIG-I and MAVS, thereby inhibiting downstream signaling and consequent transcriptional induction of the IFN- $\beta$ response [181]. This mechanism seems to be specific to the NW arenaviruses TCRV, GOTV, JUNV, MACV and SABV, since Z proteins of LCMV and LASV do not directly interact with RIG-I. Therefore, in the case of NW arenaviruses, both NP and Z may contribute to the inhibition of the type I IFN response.

The importance of the suppression of interferon induction for successful viral replication was recently demonstrated by the observation that the IFN- $\alpha$ induced cellular factor tetherin is able to inhibit arenavirus spread. Tetherin is a membran-associated protein and is understood to function as part of IFN-induced innate immunity against enveloped viruses. It has been shown to prevent HIV-1 release by retaining fully formed progeny virions on the surfaces of infected cells [183]. Importantly, tetherin inhibited both the release of LASV Z-induced VLPs [184] and the egress of infectious LASV and MACV [185]. The potential contribution of NW arenavirus $Z$ proteins to the suppression of the host cell interferon response may result in reduced tetherin expression, thus enabling efficient virus spread. 


\section{Arenavirus $Z$ protein as an antiviral target}

Currently, there is no effective antiviral therapy available for combating human pathogenic arenaviruses. Particularly in patients suffering from VHF, the difference between severe outcome and recovery appears to be associated with the viral load [186]. Antivirals that reduce the amount of infectious particles, even transiently, may be effective and may thus have an important impact on the progress of disease. Its multifunctional nature and its important role in the viral life cycle make the $\mathrm{Z}$ protein an attractive target for antiviral intervention. As a consequence, recent years have seen great efforts being made in the development of novel approaches that target either the production or function of $\mathrm{Z}$ protein.

One such approach is the down-regulation of gene expression through RNA interference (RNAi) using small interfering RNAs (siRNAs) that direct a sequence-specific degradation process of mRNA in mammalian cells. Several reports have demonstrated the efficiency and specificity of synthetic or vector-based siRNAs in the inhibition of arenavirus replication [187-189]. Using a recombinant adenoviral delivery system, RNAi-mediated targeting of $\mathrm{Z}$ mRNA efficiently inhibited LCMV multiplication in acutely infected cells [187]. Interestingly, the same study showed that RNAi treatment was also effective in clearing persistently LCMV-infected cells. Effective inhibition of virus replication by treating cells with Z-specific siRNAs has also been demonstrated for NW arenavirus JUNV [189]. Taken together, these data demonstrate the feasibility of RNAi targeting of $Z$ protein to achieve inhibition of arenavirus replication. RNAi treatment should thus be given serious consideration as a molecular therapeutic strategy in the fight against arenavirus infections in humans.

The critical importance of the highly conserved $\mathrm{Zn}^{++}$-binding RING domain of $\mathrm{Z}$ to viral replication makes this motif an interesting antiviral target. A zinc-reactive disulfide compound (NSC20625) significantly reduced the replication of JUNV, TCRV, and PICV [190]. Treatment of LCMV particles with NSC20625 allowed virions to attach and enter cells, but hindered subsequent viral RNA replication. Extended studies with JUNV revealed that NSC20625 causes a block during the uncoating of viral nucleocapsids from endosomes [191]. Further investigation of the mechanism underlying the antiviral properties of NSC20625 showed that this compound induced unfolding and oligomerization of $\mathrm{Z}$ to high-molecular-mass aggregates, presumably through irreversible modifications of the intermolecular disulfide bonds of the cysteine residues in the RING finger domain [192]. Notably, perturbation of the RING domain structure by NSC20625 seems to be specific to arenavirus Z proteins, since cellular RING finger proteins such as PML remain unaffected [192]. Interestingly, NSC20625 blocks interaction between Z protein and PML, thereby suppressing Z-mediated redistribution of PML-formed nuclear bodies [193]. Together, these observations indicate that NSC20625 represents a promising lead compound for the development of a new class of antiarenavirus inhibitors.

In summary, due to its essential roles in the arenavirus replication cycle, the $\mathrm{Z}$ protein represents an important antiviral target. This should pave the way towards the exploration of novel therapeutic strategies for counteracting infection by human pathogenic arenaviruses and especially those that cause life threatening VHF. 


\section{Concluding remarks and future outlook}

Great progress has been made in defining both the viral and cellular determinants that are important to the arenavirus life cycle and, in particular, the role of the multiple functions of the $\mathrm{Z}$ protein (summarized in Table 1). $\mathrm{Z}$ is a critical regulator of replication, the main driving force for the release of infectious progeny, a structural component of virus particles and, an IFN antagonist. Additionally, Z has been implicated in a number of virus-host interactions. The diverse functions of $Z$ are facilitated by a combination of biochemical modification and structural properties including myristoylation, a central RING domain, and late domain motifs that are important to the virus release process. Initial achievements in employing $\mathrm{Z}$ as an antiviral target further highlight its critical importance to the viral life cycle. However, a number of key aspects concerning replication, assembly, and budding remain unclear. Urgent questions include: (i) How is $\mathrm{Z}$ protein transported to particle assembly sites? Intracellular $Z$ trafficking pathways and the mechanism underlying transport of $Z$ to the site of virus budding are not fully understood. Since the $Z$ protein mediates particle assembly and budding, studies on the intracellular localization of $\mathrm{Z}$ should also provide insight into the mechanisms of arenavirus assembly. (ii) When and where does $Z$ protein engage glycoprotein GP and RNPs during the virus assembly process? Although genomic RNA, GP, NP, and L are non-essential for the formation of lipid-enveloped particles, infectious particle production requires their incorporation. (iii) What are the host factors that are involved in the late events of virus release? Arenavirus budding occurs at the plasma membrane, but the preceding steps involved in particle assembly and egress from host cells remain unexplained. These are important areas for future research and will provide critical new information on the cell biology and pathogenesis of arenaviruses. Moreover, a full molecular understanding of how arenaviruses employ cellular resources for their successful replication will open new strategies for the development of novel antivirals in the fight against the severe diseases caused by human pathogenic arenaviruses. 
Table 1. Summary of $Z$ protein-protein interactions

\begin{tabular}{|c|c|c|c|c|}
\hline \multicolumn{5}{|c|}{ Inter-arenaviral protein interactions } \\
\hline $\begin{array}{l}\text { Interaction } \\
\text { partner }\end{array}$ & Function & $\begin{array}{l}\text { Domain/motif } \\
\text { of } Z \text { protein }\end{array}$ & $\begin{array}{l}\text { Shown } \\
\text { for }\end{array}$ & Citations \\
\hline GP & $\begin{array}{l}\text { Z-GP interaction through } \\
\text { association of } Z \text { with SSP of } \\
\text { GP, recruitment of GP into } \\
\text { Z-driven VLPs }\end{array}$ & $\begin{array}{l}\text { N-terminal } \\
\text { myristoylation }\end{array}$ & $\begin{array}{l}\text { LASV } \\
\text { LCMV }\end{array}$ & $\begin{array}{l}{[72]} \\
{[106]}\end{array}$ \\
\hline \multirow[t]{2}{*}{$\mathbf{L}$} & $\begin{array}{l}\text { Inhibitory effect on } \\
\text { transcription and replication } \\
\text { by locking a polymerase-- } \\
\text { template complex }\end{array}$ & $\begin{array}{l}\text { RING domain } \\
\text { conserved W36 } \\
\text { residue in } \\
\text { LCMV Z }\end{array}$ & $\begin{array}{l}\text { LCMV } \\
\text { TCRV }\end{array}$ & $\begin{array}{l}{[85]} \\
{[90]} \\
{[91]}\end{array}$ \\
\hline & Z-L interaction & RING domain & TCRV & [85] \\
\hline \multirow{4}{*}{ NP } & $\begin{array}{l}\text { Z-NP interaction, } \\
\text { recruitment of NP into VLPs }\end{array}$ & $\begin{array}{l}\text { RING domain } \\
\text { Residue L79 }\end{array}$ & JUNV & [118] \\
\hline & $\begin{array}{l}\text { Recruitment of NP into } \\
\text { VLPs, enhancement of } \\
\text { TCRV Z-mediated budding }\end{array}$ & ASAP motif & TCRV & [117] \\
\hline & $\begin{array}{l}\text { Recruitment of NP into } \\
\text { VLPs, enhancement of } \\
\text { TCRV Z-mediated budding }\end{array}$ & YLCL motif & TCRV & [117] \\
\hline & $\begin{array}{l}\text { NP incorporation into Z- } \\
\text { induced VLPs }\end{array}$ & YLCL motif & MOPV & [124] \\
\hline \multirow{2}{*}{ Z } & $\begin{array}{l}\text { Association with membranes, } \\
\text { intracellular targeting }\end{array}$ & $\begin{array}{l}\text { N-terminal } \\
\text { myristoylation }\end{array}$ & $\begin{array}{l}\text { LASV } \\
\text { LCMV }\end{array}$ & $\begin{array}{l}71] \\
{[70]}\end{array}$ \\
\hline & $\begin{array}{l}\text { Self-association, } \\
\text { multimerization }\end{array}$ & $\begin{array}{l}\text { RING domain, } \\
\text { N-terminal } \\
\text { myristoylation }\end{array}$ & $\begin{array}{l}\text { LCMV } \\
\text { JUNV } \\
\text { TCRV }\end{array}$ & $\begin{array}{l}{[77]} \\
{[73]}\end{array}$ \\
\hline
\end{tabular}

\begin{tabular}{|c|c|c|c|c|}
\hline \multicolumn{5}{|c|}{ Virus-host cell protein interactions } \\
\hline $\begin{array}{l}\text { Interaction } \\
\text { partner }\end{array}$ & Function & $\begin{array}{l}\text { Domain/motif } \\
\text { of } Z \text { protein }\end{array}$ & $\begin{array}{l}\text { Shown } \\
\text { for }\end{array}$ & Citations \\
\hline Alix/AiP1 & NP-Z interaction & YLCL motif & MOPV & {$[124]$} \\
\hline eIF-4E & $\begin{array}{l}\text { Repression of eIF-4E } \\
\text { dependent translation }\end{array}$ & RING domain & LCMV & {$[168]$} \\
\hline Nedd4 & $\begin{array}{l}\text { Exploitation of the VPS } \\
\text { pathway for virus release }\end{array}$ & PPPY motif & LASV & $\begin{array}{l}\text { Present } \\
\text { study }\end{array}$ \\
\hline $\mathbf{P 0}$ & unknown & unknown & LCMV & [166] \\
\hline PML & $\begin{array}{l}\text { Relocalization of PML from } \\
\text { the nucleus to the cytoplasm } \\
\text { and therefore evasion of host } \\
\text { cell apoptosis }\end{array}$ & unknown & LCMV & {$[166]$} \\
\hline PRH & $\begin{array}{l}\text { Inhibition of the } \\
\text { antiproliferative effect } \\
\text { of PRH, favoring viral } \\
\text { replication and leading to } \\
\text { pathogenesis }\end{array}$ & unknown & LCMV & {$[170]$} \\
\hline RIG-I & $\begin{array}{l}\text { Inhibition of type-I IFN } \\
\text { induction }\end{array}$ & unknown & $\begin{array}{l}\text { JUNV } \\
\text { GTOV } \\
\text { MACV } \\
\text { SABV }\end{array}$ & {$[181]$} \\
\hline Tsg101 & $\begin{array}{l}\text { Exploitation of the VPS } \\
\text { pathway for virus release }\end{array}$ & $\begin{array}{l}\text { PTAP and } \\
\text { PPPY motifs }\end{array}$ & $\begin{array}{l}\text { LCMV } \\
\text { LASV }\end{array}$ & $\begin{array}{l}{[130]} \\
{[129]} \\
\text { Present } \\
\text { study }\end{array}$ \\
\hline
\end{tabular}




\section{Acknowledgments}

The authors are grateful to Stephan Becker, Wolfgang Garten and Hans-Dieter Klenk for their continued support and all their valuable ideas and input that were essential to the progress of the arenavirus work in Marburg. We thank Wolfgang Garten for critical reading of the manuscript and helpful comments. We gratefully acknowledge Jeremy Cloot for his editing work on the manuscript. All electron microscopic images shown in this article were kindly provided by Larissa Kolesnikova. This work was supported by grants from the Deutsche Forschungsgemeinschaft (Ga-282/4-1, Ga282/5-1, SFB 535, SFB 593, and the Schwerpunktprogramm SPP 1175) and the FAZIT foundation. Sarah Katharina Fehling was supported by a fellowship from the Philipps-University Marburg. Frank Lennartz was supported by a fellowship from the "Studienstiftung des deutschen Volkes". We apologize to those whose primary research is only indirectly cited in the referenced reviews.

\section{Conflict of Interest}

The authors stated that there are no conflicts of interest regarding the publication of this article.

\section{List of abbreviations}

BSL-4 biosafety level 4

eIF4E eukaryotic translation initiation factor 4E

ESCRT endosomal sorting complex required for transport

GP glycoprotein

GP-C glycoprotein precursor

IFN interferon

IKK $\quad$ I $\quad$ B kinase epsilon

IRF-3 interferon regulatory factor 3

JUNV Junin virus

kDA kilo Dalton

L L protein, arenavirus polymerase

LASV Lassa virus

LCMV lymphocytic choriomeningitis virus

NF-кB nuclear factor kappa light chain enhancer of activated B cells

Nedd4 neural precursor cell expressed developmentally down-regulated protein 4

$\mathrm{NP}$ nucleoprotein

P0 ribosomal protein $\mathrm{P} 0$

PML promyelocytic leukemia protein

PRH proline-rich homeodomain protein

RIG-I retinoic acid inducible gene I

RING really interesting new gene

RNA ribonucleic acid

RNAi RNA interference 
SSP stable signal peptide

TCRV Tacaribe virus

Tsg101 tumor susceptibility gene 101

VLP virus-like particle

$\mathrm{Z}$ protein $\quad$ zinc-binding matrix protein

\section{References and Notes}

1. Briese, T.; Paweska, J.T.; McMullan, L.K.; Hutchison, S.K.; Street, C.; Palacios, G.; Khristova, M.L.; Weyer, J.; Swanepoel, R.; Egholm, M.; Nichol, S.T.; Lipkin, W.I. Genetic detection and characterization of Lujo virus, a new hemorrhagic fever-associated arenavirus from southern Africa. PLoS Pathog 2009, 5, e1000455.

2. Buckley, S.M.; Casals, J.; Downs, W.G. Isolation and antigenic characterization of Lassa virus. Nature 1970, 227, 174.

3. Smadel, J.E.; Wall, M.J. Identification of the Virus of Lymphocytic Choriomeningitis. $J$ Bacteriol 1941, 41, 421-430.

4. Emonet, S.; Lemasson, J.J.; Gonzalez, J.P.; de Lamballerie, X.; Charrel, R.N. Phylogeny and evolution of old world arenaviruses. Virology 2006, 350, 251-257.

5. Lecompte, E.; ter Meulen, J.; Emonet, S.; Daffis, S.; Charrel, R.N. Genetic identification of Kodoko virus, a novel arenavirus of the African pigmy mouse (Mus Nannomys minutoides) in West Africa. Virology 2007, 364, 178-183.

6. Gunther, S.; Hoofd, G.; Charrel, R.; Roser, C.; Becker-Ziaja, B.; Lloyd, G.; Sabuni, C.; Verhagen, R.; van der Groen, G.; Kennis, J.; Katakweba, A.; Machang'u, R.; Makundi, R.; Leirs, H. Mopeia virus-related arenavirus in natal multimammate mice, Morogoro, Tanzania. Emerg Infect Dis 2009, 15, 2008-2012.

7. Delgado, S.; Erickson, B.R.; Agudo, R.; Blair, P.J.; Vallejo, E.; Albarino, C.G.; Vargas, J.; Comer, J.A.; Rollin, P.E.; Ksiazek, T.G.; Olson, J.G.; Nichol, S.T. Chapare virus, a newly discovered arenavirus isolated from a fatal hemorrhagic fever case in Bolivia. PLoS Pathog 2008, 4, e1000047.

8. Charrel, R.N.; Feldmann, H.; Fulhorst, C.F.; Khelifa, R.; de Chesse, R.; de Lamballerie, X. Phylogeny of New World arenaviruses based on the complete coding sequences of the small genomic segment identified an evolutionary lineage produced by intrasegmental recombination. Biochem Biophys Res Commun 2002, 296, 1118-1124.

9. Bowen, M.D.; Peters, C.J.; Nichol, S.T. The phylogeny of New World (Tacaribe complex) arenaviruses. Virology 1996, 219, 285-290.

10. Downs, W.G.; Anderson, C.R.; Spence, L.; Aitken, T.H.; Greenhall, A.H. Tacaribe virus, a new agent isolated from Artibeus bats and mosquitoes in Trinidad, West Indies. Am J Trop Med Hyg 1963, 12, 640-646.

11. Cogswell-Hawkinson, A.; Bowen, R.; James, S.; Gardiner, D.; Calisher, C.H.; Adams, R.; Schountz, T. Tacaribe Virus Causes Fatal Infection of An Ostensible Host, the Jamaican Fruit Bat. J Virol 2012. 
12. Ter Meulen, J.; Lukashevich, I.; Sidibe, K.; Inapogui, A.; Marx, M.; Dorlemann, A.; Yansane, M.L.; Koulemou, K.; Chang-Claude, J.; Schmitz, H. Hunting of peridomestic rodents and consumption of their meat as possible risk factors for rodent-to-human transmission of Lassa virus in the Republic of Guinea. Am J Trop Med Hyg 1996, 55, 661-666.

13. Kerneis, S.; Koivogui, L.; Magassouba, N.; Koulemou, K.; Lewis, R.; Aplogan, A.; Grais, R.F.; Guerin, P.J.; Fichet-Calvet, E. Prevalence and risk factors of Lassa seropositivity in inhabitants of the forest region of Guinea: a cross-sectional study. PLoS Negl Trop Dis 2009, 3, e548.

14. Fisher-Hoch, S.P.; Tomori, O.; Nasidi, A.; Perez-Oronoz, G.I.; Fakile, Y.; Hutwagner, L.; McCormick, J.B. Review of cases of nosocomial Lassa fever in Nigeria: the high price of poor medical practice. BMJ 1995, 311, 857-859.

15. Monath, T.P.; Mertens, P.E.; Patton, R.; Moser, C.R.; Baum, J.J.; Pinneo, L.; Gary, G.W.; Kissling, R.E. A hospital epidemic of Lassa fever in Zorzor, Liberia, March-April 1972. Am J Trop Med Hyg 1973, 22, 773-779.

16. Carey, D.E.; Kemp, G.E.; White, H.A.; Pinneo, L.; Addy, R.F.; Fom, A.L.; Stroh, G.; Casals, J.; Henderson, B.E. Lassa fever. Epidemiological aspects of the 1970 epidemic, Jos, Nigeria. Trans $R$ Soc Trop Med Hyg 1972, 66, 402-408.

17. Bowen, G.S.; Tomori, O.; Wulff, H.; Casals, J.; Noonan, A.; Downs, W.G. Lassa fever in Onitsha, East Central State, Nigeria in 1974. Bull World Health Organ 1975, 52, 599-604.

18. Webb, P.A.; McCormick, J.B.; King, I.J.; Bosman, I.; Johnson, K.M.; Elliott, L.H.; Kono, G.K.; O'Sullivan, R. Lassa fever in children in Sierra Leone, West Africa. Trans $R$ Soc Trop Med Hyg 1986, 80, 577-582.

19. McCormick, J.B. Epidemiology and control of Lassa fever. Curr Top Microbiol Immunol 1987, 134, 69-78.

20. Omilabu, S.A.; Badaru, S.O.; Okokhere, P.; Asogun, D.; Drosten, C.; Emmerich, P.; BeckerZiaja, B.; Schmitz, H.; Gunther, S. Lassa fever, Nigeria, 2003 and 2004. Emerg Infect Dis 2005, 11, 1642-1644.

21. Ehichioya, D.U.; Hass, M.; Olschlager, S.; Becker-Ziaja, B.; Onyebuchi Chukwu, C.O.; Coker, J.; Nasidi, A.; Ogugua, O.O.; Gunther, S.; Omilabu, S.A. Lassa fever, Nigeria, 2005-2008. Emerg Infect Dis 2010, 16, 1040-1041.

22. Fichet-Calvet, E.; Rogers, D.J. Risk maps of Lassa fever in West Africa. PLoS Negl Trop Dis 2009, 3, e388.

23. Georges, A.J.; Gonzalez, J.P.; Abdul-Wahid, S.; Saluzzo, J.F.; Meunier, D.M.; McCormick, J.B. Antibodies to Lassa and Lassa-like viruses in man and mammals in the Central African Republic. Trans R Soc Trop Med Hyg 1985, 79, 78-79.

24. Safronetz, D.; Lopez, J.E.; Sogoba, N.; Traore, S.F.; Raffel, S.J.; Fischer, E.R.; Ebihara, H.; Branco, L.; Garry, R.F.; Schwan, T.G.; Feldmann, H. Detection of Lassa virus, Mali. Emerg Infect Dis 2010, 16, 1123-1126.

25. Saluzzo, J.F.; Adam, F.; McCormick, J.B.; Digoutte, J.P. Lassa fever virus in Senegal. J Infect Dis 1988, 157, 605.

26. Akoua-Koffi, C.; Ter Meulen, J.; Legros, D.; Akran, V.; Aidara, M.; Nahounou, N.; Dogbo, P.; Ehouman, A. [Detection of anti-Lassa antibodies in the Western Forest area of the Ivory Coast]. Med Trop (Mars) 2006, 66, 465-468. 
27. Zweighaft, R.M.; Fraser, D.W.; Hattwick, M.A.; Winkler, W.G.; Jordan, W.C.; Alter, M.; Wolfe, M.; Wulff, H.; Johnson, K.M. Lassa fever: response to an imported case. N Engl J Med 1977, 297, 803-807.

28. Atkin, S.; Anaraki, S.; Gothard, P.; Walsh, A.; Brown, D.; Gopal, R.; Hand, J.; Morgan, D. The first case of Lassa fever imported from Mali to the United Kingdom, February 2009. Euro Surveill 2009, 14.

29. ter Meulen, J.; Lenz, O.; Koivogui, L.; Magassouba, N.; Kaushik, S.K.; Lewis, R.; Aldis, W. Short communication: Lassa fever in Sierra Leone: UN peacekeepers are at risk. Trop Med Int Health 2001, 6, 83-84.

30. Amorosa, V.; MacNeil, A.; McConnell, R.; Patel, A.; Dillon, K.E.; Hamilton, K.; Erickson, B.R.; Campbell, S.; Knust, B.; Cannon, D.; Miller, D.; Manning, C.; Rollin, P.E.; Nichol, S.T. Imported Lassa fever, Pennsylvania, USA, 2010. Emerg Infect Dis 2010, 16, 1598-1600.

31. Haas, W.H.; Breuer, T.; Pfaff, G.; Schmitz, H.; Kohler, P.; Asper, M.; Emmerich, P.; Drosten, C.; Golnitz, U.; Fleischer, K.; Günther, S. Imported Lassa fever in Germany: surveillance and management of contact persons. Clin Infect Dis 2003, 36, 1254-1258.

32. Schmitz, H.; Kohler, B.; Laue, T.; Drosten, C.; Veldkamp, P.J.; Gunther, S.; Emmerich, P.; Geisen, H.P.; Fleischer, K.; Beersma, M.F.; Hoerauf, A. Monitoring of clinical and laboratory data in two cases of imported Lassa fever. Microbes Infect 2002, 4, 43-50.

33. Günther, S.; Emmerich, P.; Laue, T.; Kuhle, O.; Asper, M.; Jung, A.; Grewing, T.; ter Meulen, J.; Schmitz, H. Imported lassa fever in Germany: molecular characterization of a new lassa virus strain. Emerg Infect Dis 2000, 6, 466-476.

34. Mahdy, M.S.; Chiang, W.; McLaughlin, B.; Derksen, K.; Truxton, B.H.; Neg, K. Lassa fever: the first confirmed case imported into Canada. Can Dis Wkly Rep 1989, 15, 193-198.

35. Hirabayashi, Y.; Oka, S.; Goto, H.; Shimada, K.; Kurata, T.; Fisher-Hoch, S.P.; McCormick, J.B. [The first imported case of Lassa fever in Japan]. Nihon Rinsho 1989, 47, 71-75.

36. Hirabayashi, Y.; Oka, S.; Goto, H.; Shimada, K.; Kurata, T.; Fisher-Hoch, S.P.; McCormick, J.B. An imported case of Lassa fever with late appearance of polyserositis. J Infect Dis 1988, 158, 872-875.

37. Kitching, A.; Addiman, S.; Cathcart, S.; Bischop, L.; Krahe, D.; Nicholas, M.; Coakley, J.; Lloyd, G.; Brooks, T.; Morgan, D.; Turbitt, D. A fatal case of Lassa fever in London, January 2009. Euro Surveill 2009, 14.

38. Maiztegui, J.I.; McKee, K.T., Jr.; Barrera Oro, J.G.; Harrison, L.H.; Gibbs, P.H.; Feuillade, M.R.; Enria, D.A.; Briggiler, A.M.; Levis, S.C.; Ambrosio, A.M.; Halsey, N.A.; Peters, C.J. Protective efficacy of a live attenuated vaccine against Argentine hemorrhagic fever. AHF Study Group. J Infect Dis 1998, 177, 277-283.

39. Geisbert, T.W.; Jones, S.; Fritz, E.A.; Shurtleff, A.C.; Geisbert, J.B.; Liebscher, R.; Grolla, A.; Stroher, U.; Fernando, L.; Daddario, K.M.; Guttieri, M.C.; Mothe, B.R.; Larsen, T.; Hensley, L.E.; Jahrling, P.B.; Feldmann, H. Development of a new vaccine for the prevention of Lassa fever. PLoS Med 2005, 2, e183.

40. Fisher-Hoch, S.P.; McCormick, J.B. Lassa fever vaccine. Expert Rev Vaccines 2004, 3, 189-197. 
41. McCormick, J.B.; King, I.J.; Webb, P.A.; Scribner, C.L.; Craven, R.B.; Johnson, K.M.; Elliott, L.H.; Belmont-Williams, R. Lassa fever. Effective therapy with ribavirin. $N$ Engl J Med 1986, 314, 20-26.

42. Clegg, J.C.; Wilson, S.M.; Oram, J.D. Nucleotide sequence of the S RNA of Lassa virus (Nigerian strain) and comparative analysis of arenavirus gene products. Virus Res 1991, 18, 151164.

43. Riviere, Y.; Ahmed, R.; Southern, P.J.; Buchmeier, M.J.; Dutko, F.J.; Oldstone, M.B. The S RNA segment of lymphocytic choriomeningitis virus codes for the nucleoprotein and glycoproteins 1 and 2. J Virol 1985, 53, 966-968.

44. Auperin, D.D.; Galinski, M.; Bishop, D.H. The sequences of the N protein gene and intergenic region of the S RNA of pichinde arenavirus. Virology 1984, 134, 208-219.

45. Auperin, D.D.; Sasso, D.R.; McCormick, J.B. Nucleotide sequence of the glycoprotein gene and intergenic region of the Lassa virus S genome RNA. Virology 1986, 154, 155-167.

46. Djavani, M.; Lukashevich, I.S.; Sanchez, A.; Nichol, S.T.; Salvato, M.S. Completion of the Lassa fever virus sequence and identification of a RING finger open reading frame at the L RNA 5' End. Virology 1997, 235, 414-418.

47. Lukashevich, I.S.; Djavani, M.; Shapiro, K.; Sanchez, A.; Ravkov, E.; Nichol, S.T.; Salvato, M.S. The Lassa fever virus L gene: nucleotide sequence, comparison, and precipitation of a predicted $250 \mathrm{kDa}$ protein with monospecific antiserum. J Gen Virol 1997, 78 ( Pt 3), 547-551.

48. Salvato, M.S.; Shimomaye, E.M. The completed sequence of lymphocytic choriomeningitis virus reveals a unique RNA structure and a gene for a zinc finger protein. Virology 1989, 173, 1-10.

49. Singh, M.K.; Fuller-Pace, F.V.; Buchmeier, M.J.; Southern, P.J. Analysis of the genomic L RNA segment from lymphocytic choriomeningitis virus. Virology 1987, 161, 448-456.

50. Schlie, K.; Maisa, A.; Lennartz, F.; Stroher, U.; Garten, W.; Strecker, T. Characterization of Lassa virus glycoprotein oligomerization and influence of cholesterol on virus replication. $J$ Virol 2010, 84, 983-992.

51. Neuman, B.W.; Adair, B.D.; Burns, J.W.; Milligan, R.A.; Buchmeier, M.J.; Yeager, M. Complementarity in the supramolecular design of arenaviruses and retroviruses revealed by electron cryomicroscopy and image analysis. $J$ Virol 2005, 79, 3822-3830.

52. Strecker, T.; Eichler, R.; Meulen, J.; Weissenhorn, W.; Klenk, H.D.; Garten, W.; Lenz, O. Lassa virus $\mathrm{Z}$ protein is a matrix protein and sufficient for the release of virus-like particles $J$ Virol 2003, 77, 10700-10705.

53. Salvato, M.S.; Schweighofer, K.J.; Burns, J.; Shimomaye, E.M. Biochemical and immunological evidence that the $11 \mathrm{kDa}$ zinc-binding protein of lymphocytic choriomeningitis virus is a structural component of the virus. Virus Res 1992, 22, 185-198.

54. Eichler, R.; Strecker, T.; Kolesnikova, L.; ter Meulen, J.; Weissenhorn, W.; Becker, S.; Klenk, H.D.; Garten, W.; Lenz, O. Characterization of the Lassa virus matrix protein Z: electron microscopic study of virus-like particles and interaction with the nucleoprotein (NP). Virus Res 2004, 100, 249-255.

55. Cao, W.; Henry, M.D.; Borrow, P.; Yamada, H.; Elder, J.H.; Ravkov, E.V.; Nichol, S.T.; Compans, R.W.; Campbell, K.P.; Oldstone, M.B. Identification of alpha-dystroglycan as a 
receptor for lymphocytic choriomeningitis virus and Lassa fever virus. Science 1998, 282, 20792081.

56. Spiropoulou, C.F.; Kunz, S.; Rollin, P.E.; Campbell, K.P.; Oldstone, M.B. New World arenavirus clade $\mathrm{C}$, but not clade $\mathrm{A}$ and $\mathrm{B}$ viruses, utilizes alpha-dystroglycan as its major receptor. J Virol 2002, 76, 5140-5146.

57. Shimojima, M.; Stroher, U.; Ebihara, H.; Feldmann, H.; Kawaoka, Y. Identification of cell surface molecules involved in dystroglycan-independent Lassa virus cell entry. J Virol 2012, 86, 2067-2078.

58. Shimojima, M.; Kawaoka, Y. Cell Surface Molecules Involved in Infection Mediated by Lymphocytic Choriomeningitis Virus Glycoprotein. J Vet Med Sci 2012.

59. Radoshitzky, S.R.; Abraham, J.; Spiropoulou, C.F.; Kuhn, J.H.; Nguyen, D.; Li, W.; Nagel, J.; Schmidt, P.J.; Nunberg, J.H.; Andrews, N.C.; Farzan, M.; Choe, H. Transferrin receptor 1 is a cellular receptor for New World haemorrhagic fever arenaviruses. Nature 2007, 446, 92-96.

60. Martinez, M.G.; Cordo, S.M.; Candurra, N.A. Characterization of Junin arenavirus cell entry. $J$ Gen Virol 2007, 88, 1776-1784.

61. Borrow, P.; Oldstone, M.B. Mechanism of lymphocytic choriomeningitis virus entry into cells. Virology 1994, 198, 1-9.

62. Quirin, K.; Eschli, B.; Scheu, I.; Poort, L.; Kartenbeck, J.; Helenius, A. Lymphocytic choriomeningitis virus uses a novel endocytic pathway for infectious entry via late endosomes. Virology 2008, 378, 21-33.

63. Kunz, S. Receptor binding and cell entry of Old World arenaviruses reveal novel aspects of virus-host interaction. Virology 2009, 387, 245-249.

64. Pasqual, G.; Rojek, J.M.; Masin, M.; Chatton, J.Y.; Kunz, S. Old world arenaviruses enter the host cell via the multivesicular body and depend on the endosomal sorting complex required for transport. PLoS Pathog 2011, 7, e1002232.

65. Klewitz, C.; Klenk, H.D.; ter Meulen, J. Amino acids from both N-terminal hydrophobic regions of the Lassa virus envelope glycoprotein GP-2 are critical for $\mathrm{pH}$-dependent membrane fusion and infectivity. J Gen Virol 2007, 88, 2320-2328.

66. Meyer, B.J.; Southern, P.J. Concurrent sequence analysis of $5^{\prime}$ and $3^{\prime}$ RNA termini by intramolecular circularization reveals $5^{\prime}$ nontemplated bases and $3^{\prime}$ terminal heterogeneity for lymphocytic choriomeningitis virus mRNAs. J Virol 1993, 67, 2621-2627.

67. Lee, K.J.; Novella, I.S.; Teng, M.N.; Oldstone, M.B.; de La Torre, J.C. NP and L proteins of lymphocytic choriomeningitis virus (LCMV) are sufficient for efficient transcription and replication of LCMV genomic RNA analogs. J Virol 2000, 74, 3470-3477.

68. Lopez, N.; Jacamo, R.; Franze-Fernandez, M.T. Transcription and RNA replication of tacaribe virus genome and antigenome analogs require $\mathrm{N}$ and $\mathrm{L}$ proteins: $\mathrm{Z}$ protein is an inhibitor of these processes. J Virol 2001, 75, 12241-12251.

69. Farazi, T.A.; Waksman, G.; Gordon, J.I. The biology and enzymology of protein Nmyristoylation. J Biol Chem 2001, 276, 39501-39504.

70. Perez, M.; Greenwald, D.L.; de la Torre, J.C. Myristoylation of the RING finger Z protein is essential for arenavirus budding. $J$ Virol 2004, 78, 11443-11448. 
71. Strecker, T.; Maisa, A.; Daffis, S.; Eichler, R.; Lenz, O.; Garten, W. The role of myristoylation in the membrane association of the Lassa virus matrix protein Z. Virol J 2006, 3, 93.

72. Capul, A.A.; Perez, M.; Burke, E.; Kunz, S.; Buchmeier, M.J.; de la Torre, J.C. Arenavirus Zglycoprotein association requires $\mathrm{Z}$ myristoylation but not functional RING or late domains. $J$ Virol 2007, 81, 9451-9460.

73. Loureiro, M.E.; Wilda, M.; Levingston Macleod, J.M.; D'Antuono, A.; Foscaldi, S.; Marino Buslje, C.; Lopez, N. Molecular determinants of arenavirus Z protein homo-oligomerization and L polymerase binding. J Virol 2011, 85, 12304-12314.

74. Cordo, S.M.; Candurra, N.A.; Damonte, E.B. Myristic acid analogs are inhibitors of Junin virus replication. Microbes Infect 1999, 1, 609-614.

75. Silverman, L.; Resh, M.D. Lysine residues form an integral component of a novel NH2-terminal membrane targeting motif for myristylated pp60v-src. J Cell Biol 1992, 119, 415-425.

76. Volpon, L.; Osborne, M.J.; Capul, A.A.; de la Torre, J.C.; Borden, K.L. Structural characterization of the Z RING-eIF4E complex reveals a distinct mode of control for eIF4E. Proc Natl Acad Sci U S A 2010, 107, 5441-5446.

77. Kentsis, A.; Gordon, R.E.; Borden, K.L. Self-assembly properties of a model RING domain. Proc Natl Acad Sci U S A 2002, 99, 667-672.

78. Kentsis, A.; Gordon, R.E.; Borden, K.L. Control of biochemical reactions through supramolecular RING domain self-assembly. Proc Natl Acad Sci U S A 2002, 99, 15404-15409.

79. Kentsis, A.; Dwyer, E.C.; Perez, J.M.; Sharma, M.; Chen, A.; Pan, Z.Q.; Borden, K.L. The RING domains of the promyelocytic leukemia protein PML and the arenaviral protein $\mathrm{Z}$ repress translation by directly inhibiting translation initiation factor eIF4E. J Mol Biol 2001, 312, 609623.

80. Freed, E.O. Viral late domains. J Virol 2002, 76, 4679-4687.

81. May, E.R.; Armen, R.S.; Mannan, A.M.; Brooks, C.L. 3rd The flexible C-terminal arm of the Lassa arenavirus Z-protein mediates interactions with multiple binding partners. Proteins 2010, 78, 2251-2264.

82. Garcin, D.; Rochat, S.; Kolakofsky, D. The Tacaribe arenavirus small zinc finger protein is required for both mRNA synthesis and genome replication. $J$ Virol 1993, 67, 807-812.

83. Cornu, T.I.; de la Torre, J.C. RING finger $\mathrm{Z}$ protein of lymphocytic choriomeningitis virus (LCMV) inhibits transcription and RNA replication of an LCMV S-segment minigenome. $J$ Virol 2001, 75, 9415-9426.

84. Cornu, T.I.; Feldmann, H.; de la Torre, J.C. Cells expressing the RING finger Z protein are resistant to arenavirus infection. $J$ Virol 2004, 78, 2979-2983.

85. Jacamo, R.; Lopez, N.; Wilda, M.; Franze-Fernandez, M.T. Tacaribe virus Z protein interacts with the L polymerase protein to inhibit viral RNA synthesis. J Virol 2003, 77, 10383-10393.

86. Kranzusch, P.J.; Schenk, A.D.; Rahmeh, A.A.; Radoshitzky, S.R.; Bavari, S.; Walz, T.; Whelan, S.P. Assembly of a functional Machupo virus polymerase complex. Proc Natl Acad Sci U S A 2010, 107, 20069-20074.

87. Wilda, M.; Lopez, N.; Casabona, J.C.; Franze-Fernandez, M.T. Mapping of the tacaribe arenavirus Z-protein binding sites on the L protein identified both amino acids within the 
putative polymerase domain and a region at the $\mathrm{N}$ terminus of $\mathrm{L}$ that are critically involved in binding. $J$ Virol 2008, 82, 11454-11460.

88. Brunotte, L.; Lelke, M.; Hass, M.; Kleinsteuber, K.; Becker-Ziaja, B.; Gunther, S. Domain structure of Lassa virus L protein. $J$ Virol 2011, 85, 324-333.

89. Capul, A.A.; de la Torre, J.C.; Buchmeier, M.J. Conserved residues in Lassa fever virus Z protein modulate viral infectivity at the level of the ribonucleoprotein. $J$ Virol 2011, 85, 31723178 .

90. Cornu, T.I.; de la Torre, J.C. Characterization of the arenavirus RING finger Z protein regions required for Z-mediated inhibition of viral RNA synthesis. J Virol 2002, 76, 6678-6688.

91. Kranzusch, P.J.; Whelan, S.P. Arenavirus Z protein controls viral RNA synthesis by locking a polymerase-promoter complex. Proc Natl Acad Sci U S A 2011, 108, 19743-19748.

92. Lenard, J. Negative-strand virus M and retrovirus MA proteins: all in a family? Virology 1996, 216, 289-298.

93. Mebatsion, T.; Weiland, F.; Conzelmann, K.K. Matrix protein of rabies virus is responsible for the assembly and budding of bullet-shaped particles and interacts with the transmembrane spike glycoprotein G. J Virol 1999, 73, 242-250.

94. Newcomb, W.W.; Brown, J.C. Role of the vesicular stomatitis virus matrix protein in maintaining the viral nucleocapsid in the condensed form found in native virions. $J$ Virol 1981, 39, 295-299.

95. Eichler, R.; Lenz, O.; Strecker, T.; Garten, W. Signal peptide of Lassa virus glycoprotein GP-C exhibits an unusual length. FEBS Lett 2003, 538, 203-206.

96. Buchmeier, M.J.; Oldstone, M.B. Protein structure of lymphocytic choriomeningitis virus: evidence for a cell-associated precursor of the virion glycopeptides. Virology 1979, 99, 111-120.

97. Beyer, W.R.; Popplau, D.; Garten, W.; von Laer, D.; Lenz, O. Endoproteolytic processing of the lymphocytic choriomeningitis virus glycoprotein by the subtilase SKI-1/S1P. J Virol 2003, 77, 2866-2872.

98. Lenz, O.; ter Meulen, J.; Klenk, H.D.; Seidah, N.G.; Garten, W. The Lassa virus glycoprotein precursor GP-C is proteolytically processed by subtilase SKI-1/S1P. Proc Natl Acad Sci U S A 2001, 98, 12701-12705.

99. Rojek, J.M.; Lee, A.M.; Nguyen, N.; Spiropoulou, C.F.; Kunz, S. Site 1 protease is required for proteolytic processing of the glycoproteins of the South American hemorrhagic fever viruses Junin, Machupo, and Guanarito. J Virol 2008, 82, 6045-6051.

100. Buchmeier, M.J.; Southern, P.J.; Parekh, B.S.; Wooddell, M.K.; Oldstone, M.B. Site-specific antibodies define a cleavage site conserved among arenavirus GP-C glycoproteins. J Virol 1987, 61, 982-985.

101. Eichler, R.; Lenz, O.; Strecker, T.; Eickmann, M.; Klenk, H.D.; Garten, W. Identification of Lassa virus glycoprotein signal peptide as a trans-acting maturation factor. EMBO Rep 2003, 4 , 1084-1088.

102. York, J.; Nunberg, J.H. A novel zinc-binding domain is essential for formation of the functional Junin virus envelope glycoprotein complex. $J$ Virol 2007, 81, 13385-13391.

103. Briknarova, K.; Thomas, C.J.; York, J.; Nunberg, J.H. Structure of a zinc-binding domain in the Junin virus envelope glycoprotein. J Biol Chem 2011, 286, 1528-1536. 
104. Eichler, R.; Lenz, O.; Strecker, T.; Eickmann, M.; Klenk, H.D.; Garten, W. Lassa virus glycoprotein signal peptide displays a novel topology with an extended endoplasmic reticulum luminal region. J Biol Chem 2004, 279, 12293-12299.

105. Agnihothram, S.S.; York, J.; Trahey, M.; Nunberg, J.H. Bitopic membrane topology of the stable signal peptide in the tripartite Junin virus GP-C envelope glycoprotein complex. $J$ Virol 2007, 81, 4331-4337.

106. Schlie, K.; Maisa, A.; Freiberg, F.; Groseth, A.; Strecker, T.; Garten, W. Viral protein determinants of Lassa virus entry and release from polarized epithelial cells. $J$ Virol 2010, 84, 3178-3188.

107. Tanaka, T.; Ames, J.B.; Harvey, T.S.; Stryer, L.; Ikura, M. Sequestration of the membranetargeting myristoyl group of recoverin in the calcium-free state. Nature 1995, 376, 444-447.

108. Agnihothram, S.S.; Dancho, B.; Grant, K.W.; Grimes, M.L.; Lyles, D.S.; Nunberg, J.H. Assembly of arenavirus envelope glycoprotein GPC in detergent-soluble membrane microdomains. J Virol 2009, 83, 9890-9900.

109. Mittler, E.; Kolesnikova, L.; Strecker, T.; Garten, W.; Becker, S. Role of the transmembrane domain of marburg virus surface protein GP in assembly of the viral envelope. J Virol 2007, 81, 3942-3948.

110. Kolesnikova, L.; Strecker, T.; Morita, E.; Zielecki, F.; Mittler, E.; Crump, C.; Becker, S. Vacuolar protein sorting pathway contributes to the release of Marburg virus. $J$ Virol 2009, 83, 2327-2337.

111. Baird, N.L.; York, J.; Nunberg, J.H. Arenavirus infection induces discrete cytosolic structures for RNA replication. $J$ Virol 2012.

112. Murphy, F.A.; Whitfield, S.G. Morphology and morphogenesis of arenaviruses. Bull World Health Organ 1975, 52, 409-419.

113. Noda, T.; Ebihara, H.; Muramoto, Y.; Fujii, K.; Takada, A.; Sagara, H.; Kim, J.H.; Kida, H.; Feldmann, H.; Kawaoka, Y. Assembly and budding of Ebolavirus. PLoS Pathog 2006, 2, e99.

114. Shtanko, O.; Imai, M.; Goto, H.; Lukashevich, I.S.; Neumann, G.; Watanabe, T.; Kawaoka, Y. A role for the $\mathrm{C}$ terminus of Mopeia virus nucleoprotein in its incorporation into $\mathrm{Z}$ protein-induced virus-like particles. J Virol 2010, 84, 5415-5422.

115. Ortiz-Riano, E.; Cheng, B.Y.; de la Torre, J.C.; Martinez-Sobrido, L. The C-terminal region of lymphocytic choriomeningitis virus nucleoprotein contains distinct and segregable functional domains involved in NP-Z interaction and counteraction of the type I interferon response. J Virol 2011, 85, 13038-13048.

116. Levingston Macleod, J.M.; D'Antuono, A.; Loureiro, M.E.; Casabona, J.C.; Gomez, G.A.; Lopez, N. Identification of two functional domains within the arenavirus nucleoprotein. $J$ Virol 2011, 85, 2012-2023.

117. Groseth, A.; Wolff, S.; Strecker, T.; Hoenen, T.; Becker, S. Efficient budding of the tacaribe virus matrix protein $\mathrm{z}$ requires the nucleoprotein. $J$ Virol 2010, 84, 3603-3611.

118. Casabona, J.C.; Levingston Macleod, J.M.; Loureiro, M.E.; Gomez, G.A.; Lopez, N. The RING domain and the $\mathrm{L} 79$ residue of $\mathrm{Z}$ protein are involved in both the rescue of nucleocapsids and the incorporation of glycoproteins into infectious chimeric arenavirus-like particles. J Virol 2009, 83, 7029-7039. 
119. Brunotte, L.; Kerber, R.; Shang, W.; Hauer, F.; Hass, M.; Gabriel, M.; Lelke, M.; Busch, C.; Stark, H.; Svergun, D.I.; Betzel, C.; Perbandt, M.; Gunther, S. Structure of the Lassa virus nucleoprotein revealed by X-ray crystallography, small-angle X-ray scattering, and electron microscopy. J Biol Chem 2011, 286, 38748-38756.

120. Qi, X.; Lan, S.; Wang, W.; Schelde, L.M.; Dong, H.; Wallat, G.D.; Ly, H.; Liang, Y.; Dong, C. Cap binding and immune evasion revealed by Lassa nucleoprotein structure. Nature 2010, 468, 779-783.

121. Hastie, K.M.; Liu, T.; Li, S.; King, L.B.; Ngo, N.; Zandonatti, M.A.; Woods, V.L., Jr.; de la Torre, J.C.; Saphire, E.O. Crystal structure of the Lassa virus nucleoprotein-RNA complex reveals a gating mechanism for RNA binding. Proc Natl Acad Sci USA 2011, 108, 1936519370.

122. Ortiz-Riano, E.; Cheng, B.Y.; de la Torre, J.C.; Martinez-Sobrido, L. Self-association of lymphocytic choriomeningitis virus nucleoprotein is mediated by its $\mathrm{N}$-terminal region and is not required for its anti-interferon function. $J$ Virol 2012, 86, 3307-3317.

123. Hastie, K.M.; Kimberlin, C.R.; Zandonatti, M.A.; MacRae, I.J.; Saphire, E.O. Structure of the Lassa virus nucleoprotein reveals a dsRNA-specific $3^{\prime}$ to $5^{\prime}$ exonuclease activity essential for immune suppression. Proc Natl Acad Sci U S A 2011, 108, 2396-2401.

124. Shtanko, O.; Watanabe, S.; Jasenosky, L.D.; Watanabe, T.; Kawaoka, Y. ALIX/AIP1 is required for NP incorporation into Mopeia virus Z-induced virus-like particles. J Virol 2011, 85, 36313641 .

125. Garoff, H.; Hewson, R.; Opstelten, D.J. Virus maturation by budding. Microbiol Mol Biol Rev 1998, 62, 1171-1190.

126. Neumann, P.; Lieber, D.; Meyer, S.; Dautel, P.; Kerth, A.; Kraus, I.; Garten, W.; Stubbs, M.T. Crystal structure of the Borna disease virus matrix protein (BDV-M) reveals ssRNA binding properties. Proc Natl Acad Sci US A 2009, 106, 3710-3715.

127. Alfadhli, A.; McNett, H.; Tsagli, S.; Bachinger, H.P.; Peyton, D.H.; Barklis, E. HIV-1 matrix protein binding to RNA. J Mol Biol 2011, 410, 653-666.

128. Saurin, A.J.; Borden, K.L.; Boddy, M.N.; Freemont, P.S. Does this have a familiar RING? Trends Biochem Sci 1996, 21, 208-214.

129. Urata, S.; Noda, T.; Kawaoka, Y.; Yokosawa, H.; Yasuda, J. Cellular factors required for Lassa virus budding. J Virol 2006, 80, 4191-4195.

130. Perez, M.; Craven, R.C.; de la Torre, J.C. The small RING finger protein Z drives arenavirus budding: implications for antiviral strategies. Proc Natl Acad Sci U S A 2003, 100, 12978-12983.

131. Bieniasz, P.D. Late budding domains and host proteins in enveloped virus release. Virology 2006, 344, 55-63.

132. Hurley, J.H. ESCRT complexes and the biogenesis of multivesicular bodies. Curr Opin Cell Biol 2008, 20, 4-11.

133. Hurley, J.H. The ESCRT complexes. Crit Rev Biochem Mol Biol 2010, 45, 463-487.

134. Wollert, T.; Wunder, C.; Lippincott-Schwartz, J.; Hurley, J.H. Membrane scission by the ESCRT-III complex. Nature 2009, 458, 172-177.

135. Babst, M. A protein's final ESCRT. Traffic 2005, 6, 2-9. 
136. Gruenberg, J.; Stenmark, H. The biogenesis of multivesicular endosomes. Nature reviews 2004, 5, 317-323.

137. Hurley, J.H.; Emr, S.D. The ESCRT complexes: structure and mechanism of a membranetrafficking network. Annu Rev Biophys Biomol Struct 2006, 35, 277-298.

138. Garrus, J.E.; von Schwedler, U.K.; Pornillos, O.W.; Morham, S.G.; Zavitz, K.H.; Wang, H.E.; Wettstein, D.A.; Stray, K.M.; Cote, M.; Rich, R.L.; Myszka, D.G.; Sundquist, W.I. Tsg101 and the vacuolar protein sorting pathway are essential for HIV-1 budding. Cell 2001, 107, 55-65.

139. Martin-Serrano, J.; Zang, T.; Bieniasz, P.D. HIV-1 and Ebola virus encode small peptide motifs that recruit Tsg101 to sites of particle assembly to facilitate egress. Nat Med 2001, 7, 1313-1319.

140. VerPlank, L.; Bouamr, F.; LaGrassa, T.J.; Agresta, B.; Kikonyogo, A.; Leis, J.; Carter, C.A. Tsg101, a homologue of ubiquitin-conjugating (E2) enzymes, binds the L domain in HIV type 1 Pr55(Gag). Proc Natl Acad Sci U S A 2001, 98, 7724-7729.

141. Martin-Serrano, J.; Yarovoy, A.; Perez-Caballero, D.; Bieniasz, P.D. Divergent retroviral latebudding domains recruit vacuolar protein sorting factors by using alternative adaptor proteins. Proc Natl Acad Sci U S A 2003, 100, 12414-12419.

142. Strack, B.; Calistri, A.; Craig, S.; Popova, E.; Gottlinger, H.G. AIP1/ALIX is a binding partner for HIV-1 p6 and EIAV p9 functioning in virus budding. Cell 2003, 114, 689-699.

143. von Schwedler, U.K.; Stuchell, M.; Muller, B.; Ward, D.M.; Chung, H.Y.; Morita, E.; Wang, H.E.; Davis, T.; He, G.P.; Cimbora, D.M.; Scott, A.; Krausslich, H.G.; Kaplan, J.; Morham, S.G.; Sundquist, W.I. The protein network of HIV budding. Cell 2003, 114, 701-713.

144. Chen, H.I.; Sudol, M. The WW domain of Yes-associated protein binds a proline-rich ligand that differs from the consensus established for Src homology 3-binding modules. Proc Natl Acad Sci US A 1995, 92, 7819-7823.

145. Harty, R.N.; Brown, M.E.; Wang, G.; Huibregtse, J.; Hayes, F.P. A PPxY motif within the VP40 protein of Ebola virus interacts physically and functionally with a ubiquitin ligase: implications for filovirus budding. Proc Natl Acad Sci U S A 2000, 97, 13871-13876.

146. Ingham, R.J.; Gish, G.; Pawson, T. The Nedd4 family of E3 ubiquitin ligases: functional diversity within a common modular architecture. Oncogene 2004, 23, 1972-1984.

147. Kikonyogo, A.; Bouamr, F.; Vana, M.L.; Xiang, Y.; Aiyar, A.; Carter, C.; Leis, J. Proteins related to the Nedd4 family of ubiquitin protein ligases interact with the L domain of Rous sarcoma virus and are required for gag budding from cells. Proc Natl Acad Sci US A 2001, 98, 11199-11204.

148. Vana, M.L.; Tang, Y.; Chen, A.; Medina, G.; Carter, C.; Leis, J. Role of Nedd4 and ubiquitination of Rous sarcoma virus Gag in budding of virus-like particles from cells. $J$ Virol 2004, 78, 13943-13953.

149. Blot, V.; Perugi, F.; Gay, B.; Prevost, M.C.; Briant, L.; Tangy, F.; Abriel, H.; Staub, O.; Dokhelar, M.C.; Pique, C. Nedd4.1-mediated ubiquitination and subsequent recruitment of Tsg101 ensure HTLV-1 Gag trafficking towards the multivesicular body pathway prior to virus budding. J Cell Sci 2004, 117, 2357-2367.

150. Sakurai, A.; Yasuda, J.; Takano, H.; Tanaka, Y.; Hatakeyama, M.; Shida, H. Regulation of human T-cell leukemia virus type $1(\mathrm{HTLV}-1)$ budding by ubiquitin ligase Nedd4. Microbes Infect 2004, 6, 150-156. 
151. Urata, S.; Noda, T.; Kawaoka, Y.; Morikawa, S.; Yokosawa, H.; Yasuda, J. Interaction of Tsg101 with Marburg virus VP40 depends on the PPPY motif, but not the PT/SAP motif as in the case of Ebola virus, and Tsg101 plays a critical role in the budding of Marburg virus-like particles induced by VP40, NP, and GP. J Virol 2007, 81, 4895-4899.

152. Bouamr, F.; Melillo, J.A.; Wang, M.Q.; Nagashima, K.; de Los Santos, M.; Rein, A.; Goff, S.P. PPPYVEPTAP motif is the late domain of human T-cell leukemia virus type $1 \mathrm{Gag}$ and mediates its functional interaction with cellular proteins Nedd4 and Tsg101 [corrected]. J Virol 2003, 77, 11882-11895.

153. Shields, S.B.; Piper, R.C. How ubiquitin functions with ESCRTs. Traffic 2011, 12, 1306-1317.

154. Martin-Serrano, J. The role of ubiquitin in retroviral egress. Traffic 2007, 8, 1297-1303.

155. Kamynina, E.; Tauxe, C.; Staub, O. Distinct characteristics of two human Nedd4 proteins with respect to epithelial $\mathrm{Na}(+)$ channel regulation. Am J Physiol Renal Physiol 2001, 281, F469-477.

156. Pornillos, O.; Alam, S.L.; Rich, R.L.; Myszka, D.G.; Davis, D.R.; Sundquist, W.I. Structure and functional interactions of the Tsg101 UEV domain. Embo J 2002, 21, 2397-2406.

157. Sundquist, W.I.; Schubert, H.L.; Kelly, B.N.; Hill, G.C.; Holton, J.M.; Hill, C.P. Ubiquitin recognition by the human TSG101 protein. Mol Cell 2004, 13, 783-789.

158. Urata, S.; Yasuda, J.; de la Torre, J.C. The z protein of the new world arenavirus tacaribe virus has bona fide budding activity that does not depend on known late domain motifs. $J$ Virol 2009, 83, 12651-12655.

159. Obiang, L.; Raux, H.; Ouldali, M.; Blondel, D.; Gaudin, Y. Phenotypes of vesicular stomatitis virus mutants with mutations in the PSAP motif of the matrix protein. J Gen Virol 2012, 93, 857865.

160. Reineke, E.L.; Kao, H.Y. PML: An emerging tumor suppressor and a target with therapeutic potential. Cancer Ther 2009, 7, 219-226.

161. Borden, K.L.; Campbell Dwyer, E.J.; Salvato, M.S. An arenavirus RING (zinc-binding) protein binds the oncoprotein promyelocyte leukemia protein (PML) and relocates PML nuclear bodies to the cytoplasm. $J$ Virol 1998, 72, 758-766.

162. Borden, K.L.; CampbellDwyer, E.J.; Salvato, M.S. The promyelocytic leukemia protein PML has a pro-apoptotic activity mediated through its RING domain. FEBS Lett 1997, 418, 30-34.

163. Bernardi, R.; Papa, A.; Pandolfi, P.P. Regulation of apoptosis by PML and the PML-NBs. Oncogene 2008, 27, 6299-6312.

164. Regad, T.; Chelbi-Alix, M.K. Role and fate of PML nuclear bodies in response to interferon and viral infections. Oncogene 2001, 20, 7274-7286.

165. Regad, T.; Saib, A.; Lallemand-Breitenbach, V.; Pandolfi, P.P.; de The, H.; Chelbi-Alix, M.K. PML mediates the interferon-induced antiviral state against a complex retrovirus via its association with the viral transactivator. EMBO J 2001, 20, 3495-3505.

166. Borden, K.L.; Campbelldwyer, E.J.; Carlile, G.W.; Djavani, M.; Salvato, M.S. Two RING finger proteins, the oncoprotein $\mathrm{PML}$ and the arenavirus $\mathrm{Z}$ protein, colocalize with the nuclear fraction of the ribosomal P proteins. J Virol 1998, 72, 3819-3826.

167. Pestova, T.V.; Kolupaeva, V.G.; Lomakin, I.B.; Pilipenko, E.V.; Shatsky, I.N.; Agol, V.I.; Hellen, C.U. Molecular mechanisms of translation initiation in eukaryotes. Proc Natl Acad Sci U $S$ A 2001, 98, 7029-7036. 
168. Campbell Dwyer, E.J.; Lai, H.; MacDonald, R.C.; Salvato, M.S.; Borden, K.L. The lymphocytic choriomeningitis virus RING protein $\mathrm{Z}$ associates with eukaryotic initiation factor $4 \mathrm{E}$ and selectively represses translation in a RING-dependent manner. $J$ Virol 2000, 74, 3293-3300.

169. Soufi, A.; Jayaraman, P.S. PRH/Hex: an oligomeric transcription factor and multifunctional regulator of cell fate. Biochem $J \mathbf{2 0 0 8}, 412,399-413$.

170. Djavani, M.; Topisirovic, I.; Zapata, J.C.; Sadowska, M.; Yang, Y.; Rodas, J.; Lukashevich, I.S.; Bogue, C.W.; Pauza, C.D.; Borden, K.L.; Salvato, M.S. The proline-rich homeodomain (PRH/HEX) protein is down-regulated in liver during infection with lymphocytic choriomeningitis virus. J Virol 2005, 79, 2461-2473.

171. Lukashevich, I.S.; Rodas, J.D.; Tikhonov, II; Zapata, J.C.; Yang, Y.; Djavani, M.; Salvato, M.S. LCMV-mediated hepatitis in rhesus macaques: WE but not ARM strain activates hepatocytes and induces liver regeneration. Arch Virol 2004, 149, 2319-2336.

172. Lukashevich, I.S.; Djavani, M.; Rodas, J.D.; Zapata, J.C.; Usborne, A.; Emerson, C.; Mitchen, J.; Jahrling, P.B.; Salvato, M.S. Hemorrhagic fever occurs after intravenous, but not after intragastric, inoculation of rhesus macaques with lymphocytic choriomeningitis virus. $J$ Med Virol 2002, 67, 171-186.

173. Topcu, Z.; Mack, D.L.; Hromas, R.A.; Borden, K.L. The promyelocytic leukemia protein PML interacts with the proline-rich homeodomain protein PRH: a RING may link hematopoiesis and growth control. Oncogene 1999, 18, 7091-7100.

174. Zinkernagel, R.M.; Haenseler, E.; Leist, T.; Cerny, A.; Hengartner, H.; Althage, A. T cellmediated hepatitis in mice infected with lymphocytic choriomeningitis virus. Liver cell destruction by H-2 class I-restricted virus-specific cytotoxic $\mathrm{T}$ cells as a physiological correlate of the 51Cr-release assay? J Exp Med 1986, 164, 1075-1092.

175. Martinez-Sobrido, L.; Giannakas, P.; Cubitt, B.; Garcia-Sastre, A.; de la Torre, J.C. Differential inhibition of type I interferon induction by arenavirus nucleoproteins. J Virol 2007, 81, 1269612703.

176. Carnec, X.; Baize, S.; Reynard, S.; Diancourt, L.; Caro, V.; Tordo, N.; Bouloy, M. Lassa virus nucleoprotein mutants generated by reverse genetics induce a robust type I interferon response in human dendritic cells and macrophages. J Virol 2011, 85, 12093-12097.

177. Muller, S.; Geffers, R.; Gunther, S. Analysis of gene expression in Lassa virus-infected HuH-7 cells. J Gen Virol 2007, 88, 1568-1575.

178. Groseth, A.; Hoenen, T.; Weber, M.; Wolff, S.; Herwig, A.; Kaufmann, A.; Becker, S. Tacaribe virus but not junin virus infection induces cytokine release from primary human monocytes and macrophages. PLoS Negl Trop Dis 2011, 5, e1137.

179. Martinez-Sobrido, L.; Zuniga, E.I.; Rosario, D.; Garcia-Sastre, A.; de la Torre, J.C. Inhibition of the type I interferon response by the nucleoprotein of the prototypic arenavirus lymphocytic choriomeningitis virus. J Virol 2006, 80, 9192-9199.

180. Pythoud, C.; Rodrigo, W.W.; Pasqual, G.; Rothenberger, S.; Martinez-Sobrido, L.; de la Torre, J.C.; Kunz, S. Arenavirus Nucleoprotein Targets Interferon Regulatory Factor-Activating Kinase IKK \{varepsilon\}. J Virol 2012, 86, 7728-7738.

181. Fan, L.; Briese, T.; Lipkin, W.I. Z proteins of New World arenaviruses bind RIG-I and interfere with type I interferon induction. J Virol 2010, 84, 1785-1791. 
182. Zhou, S.; Cerny, A.M.; Zacharia, A.; Fitzgerald, K.A.; Kurt-Jones, E.A.; Finberg, R.W. Induction and inhibition of type I interferon responses by distinct components of lymphocytic choriomeningitis virus. J Virol 2010, 84, 9452-9462.

183. Jouvenet, N.; Neil, S.J.; Zhadina, M.; Zang, T.; Kratovac, Z.; Lee, Y.; McNatt, M.; Hatziioannou, T.; Bieniasz, P.D. Broad-spectrum inhibition of retroviral and filoviral particle release by tetherin. $J$ Virol 2009, 83, 1837-1844.

184. Sakuma, T.; Noda, T.; Urata, S.; Kawaoka, Y.; Yasuda, J. Inhibition of Lassa and Marburg virus production by tetherin. J Virol 2009, 83, 2382-2385.

185. Radoshitzky, S.R.; Dong, L.; Chi, X.; Clester, J.C.; Retterer, C.; Spurgers, K.; Kuhn, J.H.; Sandwick, S.; Ruthel, G.; Kota, K.; Boltz, D.; Warren, T.; Kranzusch, P.J.; Whelan, S.P.; Bavari, $\mathrm{S}$. Infectious Lassa virus, but not filoviruses, is restricted by BST-2/tetherin. $J$ Virol 2010, 84, 10569-10580.

186. Johnson, K.M.; McCormick, J.B.; Webb, P.A.; Smith, E.S.; Elliott, L.H.; King, I.J. Clinical virology of Lassa fever in hospitalized patients. J Infect Dis 1987, 155, 456-464.

187. Sanchez, A.B.; Perez, M.; Cornu, T.; de la Torre, J.C. RNA interference-mediated virus clearance from cells both acutely and chronically infected with the prototypic arenavirus lymphocytic choriomeningitis virus. J Virol 2005, 79, 11071-11081.

188. Muller, S.; Gunther, S. Broad-spectrum antiviral activity of small interfering RNA targeting the conserved RNA termini of Lassa virus. Antimicrob Agents Chemother 2007, 51, 2215-2218.

189. Artuso, M.C.; Ellenberg, P.C.; Scolaro, L.A.; Damonte, E.B.; Garcia, C.C. Inhibition of Junin virus replication by small interfering RNAs. Antiviral Res 2009, 84, 31-37.

190. Garcia, C.C.; Candurra, N.A.; Damonte, E.B. Antiviral and virucidal activities against arenaviruses of zinc-finger active compounds. Antivir Chem Chemother 2000, 11, 231-237.

191. Garcia, C.C.; Ellenberg, P.C.; Artuso, M.C.; Scolaro, L.A.; Damonte, E.B. Characterization of Junin virus particles inactivated by a zinc finger-reactive compound. Virus Res 2009, 143, 106113.

192. Garcia, C.C.; Djavani, M.; Topisirovic, I.; Borden, K.L.; Salvato, M.S.; Damonte, E.B. Arenavirus $\mathrm{Z}$ protein as an antiviral target: virus inactivation and protein oligomerization by zinc finger-reactive compounds. J Gen Virol 2006, 87, 1217-1228.

193. Garcia, C.C.; Topisirovic, I.; Djavani, M.; Borden, K.L.; Damonte, E.B.; Salvato, M.S. An antiviral disulfide compound blocks interaction between arenavirus $\mathrm{Z}$ protein and cellular promyelocytic leukemia protein. Biochem Biophys Res Commun 2010, 393, 625-630.

194. Timmins, J.; Schoehn, G.; Ricard-Blum, S.; Scianimanico, S.; Vernet, T.; Ruigrok, R.W.; Weissenhorn, W. Ebola virus matrix protein VP40 interaction with human cellular factors Tsg101 and Nedd4. J Mol Biol 2003, 326, 493-502.

(C) 2012 by the authors; licensee MDPI, Basel, Switzerland. This article is an open access article distributed under the terms and conditions of the Creative Commons Attribution license (http://creativecommons.org/licenses/by/3.0/). 